\title{
Building Resillience in Developing Countries Vulnerable to Large Natural Disasters
}




\section{INTERNATIONAL MONETARY FUND}

\section{IMF POLICY PAPER}

\section{BUILDING RESILIENCE IN DEVELOPING COUNTRIES VULNERABLE TO LARGE NATURAL DISASTERS}

IMF staff regularly produces papers proposing new IMF policies, exploring options for reform, or reviewing existing IMF policies and operations. The following documents have been released and are included in this package:

- A Press Release summarizing the views of the Executive Board as expressed during its May 1, 2019 consideration of the staff report.

- The Staff Report, prepared by IMF staff and completed on April 4, 2019 for the Executive Board's consideration on May 1, 2019.

The IMF's transparency policy allows for the deletion of market-sensitive information and premature disclosure of the authorities' policy intentions in published staff reports and other documents.

Electronic copies of IMF Policy Papers

are available to the public from

http://www.imf.org/external/pp/ppindex.aspx

\section{International Monetary Fund Washington, D.C.}


This page intentionally left blank 
Press Release No. 19/241

FOR IMMEDIATE RELEASE

June 26, 2019
International Monetary Fund

$70019^{\text {th }}$ Street, NW

Washington, D. C. 20431 USA

\section{IMF Executive Board Discusses Building Resilience in Developing Countries Vulnerable to Large Natural Disasters}

On May 1, 2019, the Executive Board of the International Monetary Fund (IMF) discussed an IMF staff paper on building resilience to large natural disasters and options for managing associated risks in vulnerable developing countries.

\section{Background}

Many developing countries, particularly small states, are vulnerable to natural disasters that can have large human, economic, and social costs. Recent examples of major disasters include Cyclone Idai (March 2019), which caused significant loss of life and widespread economic disruption in Mozambique and neighboring countries, and Hurricane Maria (September 2017), which caused damage to property and infrastructure estimated at some 200 percent of GDP in Dominica. As the frequency and intensity of natural disasters is projected to increase over time with climate change, the economic and social impact of disasters can also be expected to increase.

Given these costs, there are many benefits to taking actions now to enhance preparedness for natural disasters, in terms of lowering the economic and social impact, speeding up recovery, and providing greater continuity in public services. However, in many disaster-vulnerable countries, there is substantial underinvestment in resilience-building efforts, reflecting capacity constraints, large upfront costs, and limited fiscal space. International financial institutions and other development partners make available various forms of support for resilience-building, but domestic institutional capacity constraints often limit the ability of small and poorer countries to fully leverage the resources available to them.

Drawing on a substantial body of existing work by the World Bank and other agencies, the IMF staff paper recommends that vulnerable countries develop comprehensive disaster resilience strategies (DRS) in consultation with development partners and other stakeholders. The DRS should be grounded in a clear diagnostic of disaster vulnerabilities and rest on three pillars: building structural, financial, and post-disaster/social resilience. Such a strategy would support ex-ante planning, provide a framework for coordinating the work of development partners before and after disasters, and help catalyze donor support. Given its expertise in designing macroeconomic policies and frameworks, the IMF can play an important role in supporting resilience building in 
disaster-vulnerable countries in the context of its operational work with countries and its support for domestic capacity development.

\section{Executive Board Assessment ${ }^{1}$}

Executive Directors welcomed the opportunity to take stock of ongoing staff work on building resilience to natural disasters in vulnerable countries, including the efforts being made to incorporate disaster risks into macroeconomic frameworks and into Fund surveillance more generally.

Directors agreed that natural disasters can have significant and long-lasting effects on economic well-being in many developing countries, particularly small, fragile, and low-income states, and that the frequency and intensity of weather-related shocks are expected to further increase as climate change evolves. They underscored that the social and economic impact of natural disasters can be mitigated through policies to build resilience, including targeted investments in infrastructure and the effective use of available financial instruments.

Directors agreed that incorporating disaster risk is an important component of sound macroeconomic management in countries where risks of large-scale natural disasters are significant. They agreed that the Fund, in collaboration with the World Bank and other development partners, can help vulnerable countries assess the trade-offs between development needs, rising debt vulnerabilities, and the benefits of ex ante resilience building. Most Directors agreed that the Fund's approach to resilience building should extend to slower-onset disasters, which can also have a detrimental impact on countries.

Directors welcomed the suggested three-pillar approach to resilience-building as a useful framework for analyzing policy options in a systematic fashion and for identifying key priorities. They noted that the approach was informed by the Sendai Framework for Disaster Risk Reduction and the work of the World Bank on disaster risk management and insurance strategies. They agreed that many small, fragile, and low-income countries face significant capacity constraints in developing a full strategy for building resilience, which can severely impair the ability of governments to make effective use of external support, and noted that the Fund and the World Bank are well placed to assist countries in overcoming these capacity gaps. While noting the important role of development partners in supporting national efforts, Directors emphasized that government ownership is crucial in building resilience to natural disasters.

Directors saw merit in governments in vulnerable countries developing a national disaster resilience strategy (DRS), drawing on support from the international financial institutions. The Fund could take a lead role in helping countries develop a macroeconomic policy framework that adequately reflects both disaster costs and returns from resilient investment and that identifies the fiscal actions to support the policy framework. The World Bank and other development

\footnotetext{
${ }^{1}$ An explanation of any qualifiers used in summings up can be found here: http://www.imf.org/external/np/sec/misc/qualifiers.htm.
} 
banks could take a lead role in helping countries identify and assess disaster vulnerabilities and in prioritizing investment needs. Directors highlighted the need for Fund staff to collaborate closely with the World Bank in supporting country efforts, with a few Directors underscoring the core expertise of the Bank in key areas where support would be needed.

Overall, a DRS would provide a roadmap for policy design and sequencing, and facilitate coordination of donor support for national plans. Directors remarked that the DRS would focus national attention on active preparation for disasters while providing an anchor for support from development partners. Directors noted scope for further clarifying the details of coordination, sequencing, and responsibilities of different stakeholders in developing an effective country-owned DRS. They also highlighted that the development of a DRS would benefit from peer learning and experience-sharing among countries and agencies. Directors agreed that a credible DRS could help catalyze higher levels of financial support from bilateral donors, climate funds, and other sources, and welcomed the interest expressed by some Caribbean authorities in developing such strategies.

Directors emphasized that the use of risk-transfer instruments should figure more prominently in government measures to improve financial resilience to disasters, while recognizing the challenges involved in developing insurance markets that provide reasonable premium levels relative to expected annual payouts. They welcomed the efforts of donor countries to support insurance market development and strengthen risk pooling. Directors broadly supported additional work by the Fund, in collaboration with the World Bank, to analyze the role and potential contribution of state-contingent debt instruments in helping countries build resilience to natural disasters.

Directors noted that the Fund has a valuable role to play in supporting country efforts to build resilience to natural disasters, as part of its surveillance and capacity building activities. A coherent resilience strategy should fit within a medium-term macroeconomic policy framework that is consistent with maintaining debt sustainability, including under adverse shocks — an area of core Fund expertise. Staff could also contribute through analysis of the economic impact of disasters and of trade-offs between public investment and debt accumulation. Directors agreed that the Fund's lending toolkit was sufficiently flexible to provide support for disaster-vulnerable countries that face a BoP need, but most saw scope to increase access limits as well as to use the toolkit in non-traditional ways to support resilience-building. Directors encouraged giving special attention to countries prone to natural disasters in the upcoming FSAP Review and Comprehensive Surveillance Review.

Directors agreed that disaster resilience strategies need to be based on a robust diagnostic of risks and vulnerabilities and encouraged a pragmatic approach, in coordination with the World Bank. They asked for a full assessment of the Climate Change Policy Assessments being piloted in a handful of small countries, in collaboration with the World Bank, which could provide a valuable diagnostic for national authorities. 
Directors noted that building resilience to natural disasters extends to areas in which the Fund does not have relevant in-house expertise. They underscored that providing effective support to governments would require close collaboration and coordination with other institutions that have the relevant expertise, including in developing disaster resilience strategies, and called for a clear division of labor, based on respective mandates, between the Fund, the multilateral development banks, and other agencies. 


\section{INTERNATIONAL MONETARY FUND}

April 4, 2019

\section{BUILDING RESILIENCE IN DEVELOPING COUNTRIES}

\section{VULNERABLE TO LARGE NATURAL DISASTERS}

\section{EXECUTIVE SUMMARY}

Focus and Motivation: Many developing countries are vulnerable to natural disasters that can have large human and economic costs: disaster risk management for these countries is a macro-critical challenge. In recent years, the IMF has been underscoring the macroeconomic risks of climate change and natural disasters for many countries (typically either small or poor), including their limited capacity to develop, finance, and implement a full disaster risk-management strategy. This paper discusses the components of such a strategy-drawing on consultations with other international organizations and on discussions at recent high-level conferences on building disaster resilience in the Caribbean and in the Pacific regions-and looks at how support for national resilience-building from international financial institutions (IFIs) and other development partners might be better coordinated.

A Roadmap for Resilience: The paper views disaster risk management through the lens of a three-pillar strategy for building structural, financial, and post-disaster resilience. Enhancing structural resilience requires infrastructure and other investments to limit the impact of disasters (Pillar I); building financial resilience involves creating fiscal buffers and using pre-arranged financial instruments to protect fiscal sustainability and manage recovery costs (Pillar II); and post-disaster (including social) resilience requires contingency planning and related investments ensuring a speedy response to a disaster (Pillar III). A full national disaster resilience strategy (DRS) requires actions on all three pillars, grounded on a clear diagnostic.

In many small or low-income countries, there is substantial underinvestment in building structural resilience, reflecting sizable up-front costs and limited fiscal space, as well as limited use of ex-ante financing instruments such as insurance, reflecting both cost concerns and underdeveloped markets. While steps are being taken in many countries to facilitate speedy recovery and reconstruction following a disaster, there is still substantial room to strengthen response mechanisms to improve post-disaster resilience. The benefits of investing in resilience building include lower expected losses from disasters, higher returns to private investment, improved employment and output performance, and better continuity in public services after a disaster.

International financial institutions and other development partners offer various forms of support to disaster-vulnerable countries, but many countries have limited capacity to take full advantage of such support, which can be fragmented and poorly coordinated across providers. This paper argues that a fleshed out nationally-owned DRS could act as the anchor or platform for coordinated support from development partners, which would be needed both to develop 
and implement the DRS. Such a strategy, if endorsed by the various stakeholders, including Fund endorsement of the associated macroeconomic framework, could also have a strong catalytic effect in mobilizing concessional donor support.

IMF Role: Within its mandate, the Fund can play a valuable role in supporting resilience building in disaster-vulnerable countries. In particular, Fund surveillance can analyze the macroeconomic impact of disasters and of resilience-building; Fund arrangements could be used to support implementation of a DRS, including providing financing to address associated balance of payments problems; and targeted capacity-building support in areas of Fund expertise can help strengthen national capacity. The Fund, collaborating with the World Bank and others, can also bring together stakeholders-private insurers, governments, donors, climate funds - to tackle issues such as impediments to market-based risk transfer (e.g., exploring the financial viability of debt instruments with disaster clauses) or better connecting small states with the climate funds. 
Approved By Seán Nolan (SPR), Krishna Srinivasan (WHD), and Odd Per Brekk (APD)
Prepared by Aliona Cebotari and Uma Ramakrishnan (WHD), Ali Mansoor, Saad Quayyum, Marina Mendes Tavares, Mai Farid, Wei Guo, and Sibabrata Das (SPR), Alison Stuart and Scott Roger (APD), with inputs from Marshall Mills and Vimal Thakoor (AFR), Daniel Leigh, Bogdan Lissovolik, Sonia Munoz, Inci Otker, Leo Bonato, Alejandro Guerson, Takuji Komatsuzaki, and Karim Youssef (WHD), Calixte Ahokpossi, Ragnar Gudmundsson, Si Guo, Todd Schneider, Minsuk Kim, David Kloeden, and Dirk Muir (APD), and Tamon Asonuma and Tom Best (SPR).

\section{CONTENTS}

INTRODUCTION

DEALING WITH NATURAL DISASTERS: STYLIZED FACTS

A. The Economic Impact of Natural Disasters

B. State Capacity and Disaster Preparedness

A. Pillar I: Structural Resilience ___ 11

B. Pillar II: Financial Resilience ___ 16

C. Pillar III: Post-Disaster Resilience___ $\underline{22}$

TOWARD A FRAMEWORK FOR ENHANCED COORDINATED ACTION ___ _ $\underline{\mathbf{2 4}}$

A. The Case for Enhanced Coordination ___ 24

B. Developing A Disaster Resilience Strategy ___ _ 24

C. A Potential Division of Labor Across Stakeholders ___ 27

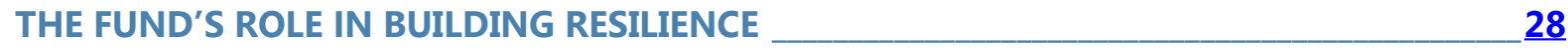

A. Engagement in Fund Surveillance___ $\underline{28}$

B. Support via the Fund's Lending Toolkit ___ $\underline{30}$

C. Supporting Capacity Development ___ $\underline{31}$

ISSUES FOR DISCUSSION _______ $\underline{33}$

References $\underline{34}$

\section{BOXES}

1. Investing in Structural Resilience-Implications for Debt Sustainability and Concessional

Financing 
2. Savings from Ex-Ante Interventions __ $\underline{15}$

3. A Case for Climate-Resilient Debt Instruments___ 21

4. The Climate Change Policy Assessment___ $\underline{26}$

5. Integrating the Cost of Natural Disasters in the Pacific Islands ___ 29

\section{FIGURES}

1. Natural Disasters: Frequency and Effects___ $\underline{7}$

2. Macroeconomic Impacts of Natural Disasters___ $\underline{9}$

3. Institutional Capacity and Access to Multilateral Climate Finance: 2003-2018___ 10

4. National Disaster Resilience Strategy____ 11

5. Benefit-Cost Ratios for Ex-Ante Interventions ___ 12

6. World Bank's Multi-Layer Risk Approach to Financing Disaster Risk___ 17

7. Limited Risk Transfer through Insurance, and Losses from Natural Disasters___

8. Choosing Optimal Risk Transfer: The Trade-offs___ 19

\section{TABLES}

1. Illustrated List of Countries at Risk of Major Natural Disasters ___ $\underline{8}$

2. Regional Sovereign Insurance Pools ___ 17

\section{ANNEXES}

I. The World Bank Group's Support for Building Resilience ___ 37

II. Natural Disasters in Sub-Saharan Africa___

III. Policies to Enhance Resilience: Examples___ $\underline{40}$

IV. The Structure of Cat Bonds___ 42

V. Optimal Risk Transfer in Smaller vs. Larger Countries___

VI. Investing in Pillars I and II - Illustrations for the ECCU and Pacific Islands ___

VII. Advanced and Emerging Asia Pacific Region: Examples of Disaster Resilience Building___ 47 


\section{INTRODUCTION}

1. Natural disasters take a large human toll and disrupt economic activity in many developing countries, particularly small states. Climate-related disasters, including hurricanes/cyclones and droughts, have been increasing in intensity and frequency over time against the backdrop of global climate change, while geological events, such as volcanic eruptions, earthquakes, and tsunamis, represent a perennial hazard.

\section{The macroeconomic significance of natural disasters depends on country conditions. In} larger countries with more diversified or affluent economies, the impact is typically local in nature, with some combination of private insurance markets and central budgetary resources providing support to disaster-hit regions; the macroeconomic impact on the national economy is usually modest. By contrast, in countries that are geographically or economically small, where key sectors are dependent on weather conditions, and/or where private insurance markets are underdeveloped, the effects of such shocks on national economic activity and production capacity can be large.

3. This paper focuses on the second group: countries where natural disasters can have a large macroeconomic impact and, hence, where building resilience to natural disasters is a macro-critical challenge. Countries that fall into this grouping are typically either small or poor or both, with limited administrative capacity to develop a disaster risk management strategy to contain the impact of adverse shocks. This paper uses the term disaster-vulnerable countries to refer to such countries.

\section{The difficulty of building resilience to natural disasters in disaster-vulnerable states was} examined in a recent Board paper (IMF, 2016a). The paper examined the specific vulnerability of small developing states to natural disasters and climate change; noted that disaster management preparations typically fall well short of what is needed; and explored how Fund policy advice and capacity-building could help countries improve disaster resilience, including via financing strategies. ${ }^{1}$ A subsequent paper (IMF, 2017a) led to the creation of a "large natural disasters" window in the Fund's emergency financing facilities, with higher access levels than for other exogenous shocks.

\section{This paper builds on these earlier works, viewing disaster risk management through the} lens of a three-pillar strategy for building structural, financial, and post-disaster (including social) resilience. It draws on the substantial body of work produced by the World Bank and other agencies on preparing for, and managing, large natural disasters (Annex I). The focus is on how best to support disaster-vulnerable countries, including both small states and larger low-income countries, in building resilience to disasters, taking account of the significant fiscal and institutional capacity constraints. A comprehensive approach to building resilience requires a combination of inputs that collectively underpin

\footnotetext{
${ }^{1}$ IMF (2016b) explored the effects of natural disasters in sub-Saharan Africa (SSA): it found that, while short-term economic effects were often muted, these shocks yielded a marked rise in malnutrition and poverty levels and had a significant adverse impact on longer-term development.
} 
a national Disaster Resilience Strategy (DRS), ${ }^{2}$ including a well-grounded diagnostic upon which the component parts of the three-pillar strategy can be built. Countries with significant capacity constraints will require assistance from development partners both to develop a sound DRS and then to implement it; the DRS can provide a platform for organizing effective collaboration across international financial institutions (IFIs) and other development partners.

6. The remainder of the paper is organized as follows. Section II reviews stylized facts regarding disaster-vulnerable countries-the scale of disasters and the challenges to building resilience. Section III discusses the main elements of a DRS, drawing upon analytical work by Fund staff, the World Bank, and other agencies, and ongoing engagement with country authorities. Section IV examines how structured collaboration among international financial institutions and development partners could help develop a coherent package of support for resilience building to small/poor capacity-constrained countries. Section $V$ discusses the areas in which the Fund can effectively support design and implementation of a DRS, reviews how Fund engagement with disaster-vulnerable countries has evolved in recent years and identifies areas for future work.

\section{DEALING WITH NATURAL DISASTERS: STYLIZED}

\section{FACTS}

\section{A. The Economic Impact of Natural Disasters}

\section{The frequency of natural disasters and the damage associated with them have been} increasing over time and are expected to intensify with ongoing climate change (Figure 1a). Small states in the Caribbean and the Pacific are particularly vulnerable to natural disasters, with annual average damage of 2-3 percent of GDP (Figure 1b). The annual average, however, masks the severity of major disasters, as illustrated by the experiences of Dominica (2017) and Grenada (2004) (Figure 1c).

8. Many developing economies that are not small states are also highly vulnerable to natural disasters, including earthquakes, floods, and slow-moving disasters such as droughts (as illustrated in Table 1). Many low-income countries in sub-Saharan Africa-dependent on rain-fed agriculture —suffer considerable damage from repeated droughts and floods (Annex II); the recent cyclone-driven disaster in Mozambique is an excellent case in point. Similarly, developing countries in the Middle East and Central Asia are also subject to drought, floods, and earthquakes; these climate vulnerabilities amplify conflictrelated challenges in some countries, such as Afghanistan and Somalia. The Asia-Pacific region is highly exposed to natural disasters such as cyclones, earthquakes, tsunamis, and volcanic activity-with South Asia and the Philippines among the most severely affected.

\footnotetext{
2 The term "Disaster Resilience Strategy" is used as a label for a comprehensive national plan to build resilience to limit the disruption caused by natural disasters; equivalent labels would include "National Disaster Plan" or "Disaster Risk Management Framework." The DRS label is chosen here for brevity and intuitive appeal.
} 


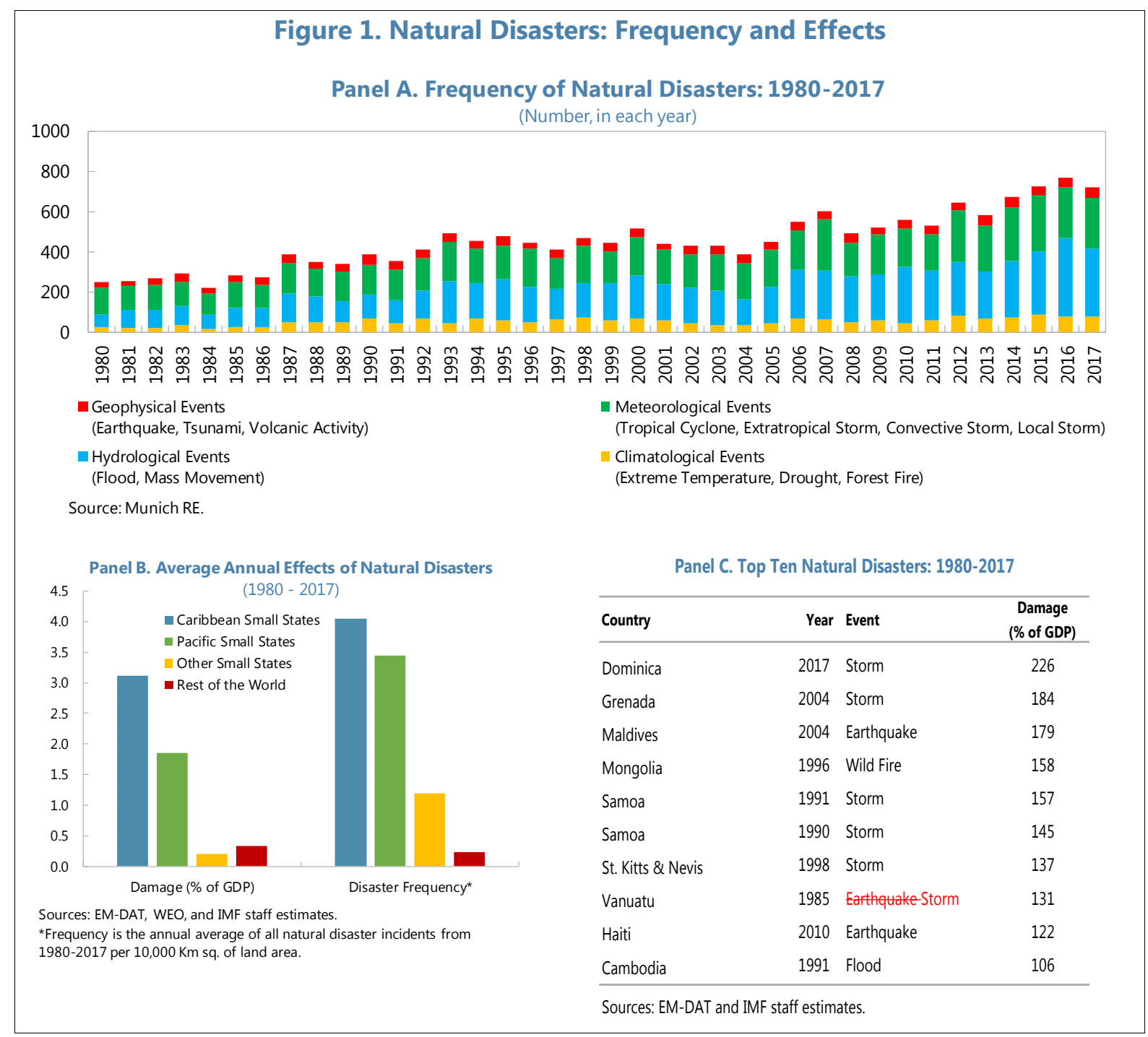


Table 1. Illustrated List of Countries at Risk of Major Natural Disasters $\mathbf{1}^{1,2}$

\begin{tabular}{|c|c|c|c|}
\hline \multicolumn{2}{|c|}{ Emerging and Developing Asia (20 countries) } & \multicolumn{2}{|c|}{ Sub-Saharan Africa (22 countries) } \\
\hline Bangladesh & Palau & Angola & Kenya \\
\hline Cambodia & Philippines & Benin & Liberia \\
\hline Fiji & Samoa & Burkina Faso & Madagascar \\
\hline Indonesia & Solomon Islands & Cabo Verde & Mali \\
\hline Kiribati & Sri Lanka & Cameroon & Mauritius \\
\hline Maldives & Timor Leste & Chad & Mozambique \\
\hline Micronesia & Tonga & Comoros & Niger \\
\hline Myanmar & Tuvalu & Eswatini & São Tomé and Príncipe \\
\hline Nepal & Vanuatu & Gambia & Senegal \\
\hline \multirow[t]{2}{*}{ Papua New Guinea } & Vietnam & Guinea & Sierra Leone \\
\hline & & Guinea-Bissau & Zimbabwe \\
\hline Latin America and the Caribbean & & \multirow{2}{*}{\multicolumn{2}{|c|}{$\begin{array}{l}\text { Middle East and Central Asia } \\
\text { (4 countries) }\end{array}$}} \\
\hline (18 countries) & & & \\
\hline Antigua and Barbuda & Guatemala & \multicolumn{2}{|l|}{ Afghanistan } \\
\hline Bahamas, The & Guyana & \multicolumn{2}{|l|}{ Djibouti } \\
\hline Belize & Haiti & \multicolumn{2}{|l|}{ Sudan } \\
\hline Chile & Honduras & \multicolumn{2}{|l|}{ Tajikistan } \\
\hline Costa Rica & Nicaragua & & \\
\hline Dominica & Jamaica & & \\
\hline Dominican Republic & St. Kitts and Nevis & & \\
\hline El Salvador & St. Lucia & & \\
\hline Grenada & St. Vincent and the & ines & \\
\hline
\end{tabular}

Source: World Economic Outlook.

${ }^{1}$ Data limitations preclude relying on any single source for an assessment of vulnerability to disasters; the listing here is illustrative and does not have any operational implications.

${ }^{2}$ Countries are included in the listing if: (1) they experienced reported cumulative damage of at least 20 percent of GDP between 1998-2017 from natural disasters that each caused damage of at least 5 percent of GDP (source: EMDAT, IMF (2016a)); or (2) they were classified as being small states at extreme or high risk of experiencing natural disasters in IMF (2016a); or (3) they are in the top quartile of countries ranked by disaster vulnerability in the World Risk Index 2018 (World Risk Report, 2018). Three countries (Guinea, Liberia, and Sri Lanka) were added on the basis of staff judgment.

\section{Natural disasters can have large and long-lasting macroeconomic effects in vulnerable}

countries. Indeed, large natural disasters causing significant damage can substantially setback output growth and contribute to a significant rise in public debt (Figure 2). Vulnerability to recurrent disasters affects medium-term growth potential, both directly through repeated adverse shocks to physical capital and indirectly through a higher effective cost of capital and higher levels of out-migration. Natural disasters also generate significant social costs in terms of lost lives, worsening food insecurity, and deterioration in human capital, with longer-term ramifications for growth and poverty in poorer countries (IMF, 2016b). These disasters also disproportionately hurt the poor, who have fewer coping mechanisms. 
Figure 2. Macroeconomic Impacts of Natural Disasters
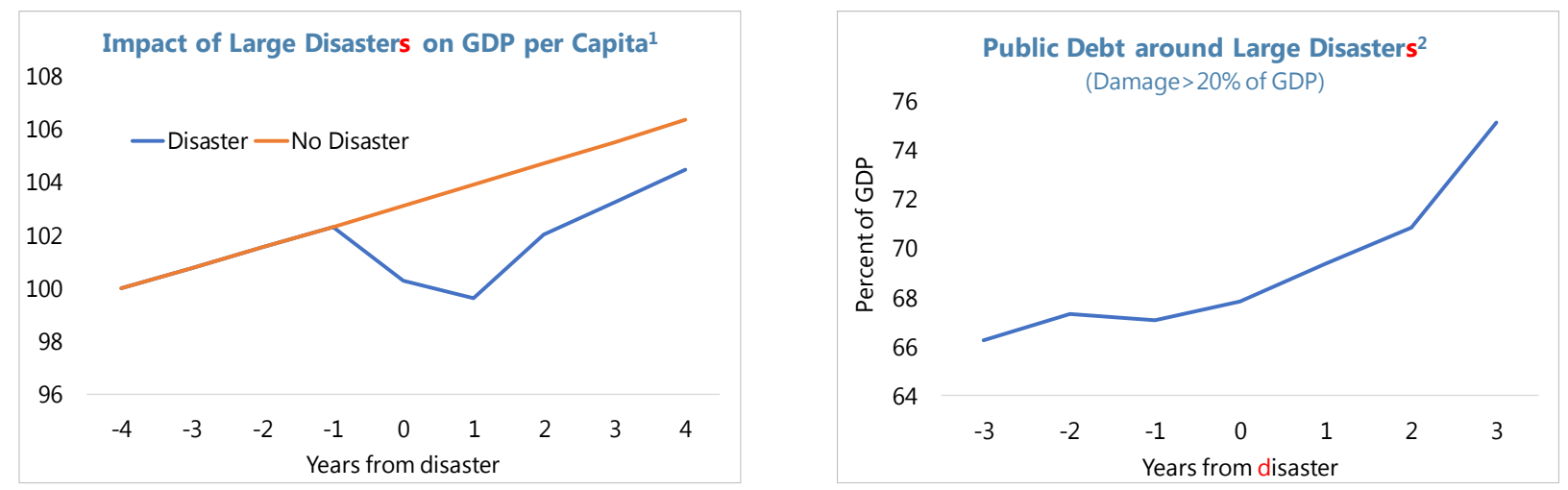

Sources: EM-DAT database and IMF staff estimates.

Note: For each country in EM-DAT database, the disaster with the largest damage in percent of GDP was identified. The sample was then restricted to only developing countries where the largest disaster caused damages of 20 percent of GDP or higher. The cross-country average growth of GDP per capita, and public debt, around the time of largest disasters were calculated for this restricted sample. For the GDP per capita chart, the orange line shows a GDP per capita path based on average growth rate in years one, two, and three prior to the largest disaster. The blue line is based on average growth of GDP per capita in year of the disaster and the years following it.

${ }^{1}$ Disasters with damage greater than 20 percent of GDP; based on average growth rate from 15 episodes in developing countries between 1991-2016.

${ }^{2}$ Average public debt for 11 episodes of large natural disasters in developing countries between 1992 to 2016 for which data are available.

\section{Fiscal space, institutional capacity, and ex-ante preparedness can help mitigate the} cost of natural disasters. Countries with fiscal space-be it financial buffers, lower debt levels, and/or significant insurance coverage - can move quickly to finance reconstruction; countries without fiscal space (e.g., due to high debt levels, disaster-related implicit and explicit contingent liabilities, low borrowing capacity or limited revenue mobilization) are constrained in their capacity to react. Similarly, ex-ante preparedness and associated institution building play an important role in limiting the output loss and humanitarian costs of natural disasters-the key theme of section III.

\section{B. State Capacity and Disaster Preparedness}

\section{The roadmap for building ex-ante resilience to large natural disasters is well established.}

The Sendai Framework for Disaster Risk Reduction for 2015-2030 outlines policy targets and action priorities to prevent new and reduce existing disaster risks. It underscores the importance of: (i) developing an understanding of the risks to which a country is exposed; (ii) strengthening disaster risk governance; (iii) investing in risk reduction; and (iv) enhancing preparedness for effectively responding to disasters. ${ }^{3}$ The World Bank has been helping countries develop disaster risk

\footnotetext{
${ }^{3}$ Adopted by the UN at the World Conference on Disaster Risk Reduction in Sendai, Japan, in March 2015 as a more ambitious successor to the 2005 Hyogo Framework, the Sendai Framework is a voluntary, non-binding agreement, which recognizes that the state has the primary role to reduce disaster risk, but that responsibility should be shared with other stakeholders including local governments, the private sector and others. It aims for a substantial reduction (continued)
} 
management (DRM) and Disaster Risk Financing and Insurance (DRFI) strategies for over a decade, organized around the five principles of i) risk identification, ii) risk reduction, iii) risk preparedness, iv) financial protection, and v) resilient recovery. The three-pillar strategy discussed in the next section, which is informed by the Sendai framework and the Bank's DRM framework (World Bank, 2019), provides an intuitive organizing framework for discussing the key elements of a DRS with Finance Ministries in a surveillance context and for better integrating the component parts into the budget process.

\section{The challenges of developing/implementing a DRS are likely to be bigger in small or} poor states. As noted above, countries that are small in geographical size and/or have large agricultural or tourism sectors dependent on variable weather conditions are particularly exposed to adverse shocks that have a large macroeconomic impact-underscoring the need for a robust DRS in such cases. But these states-typically with small populations or poor or both-also have limited domestic capacity/resources to develop a DRS and often find it difficult to manage their engagement with multiple development partners (often with diverse agendas) and financial markets in support of such a strategy.

Figure 3. Institutional Capacity and Access to Multilateral Climate Finance: 2003-2018 ${ }^{1}$

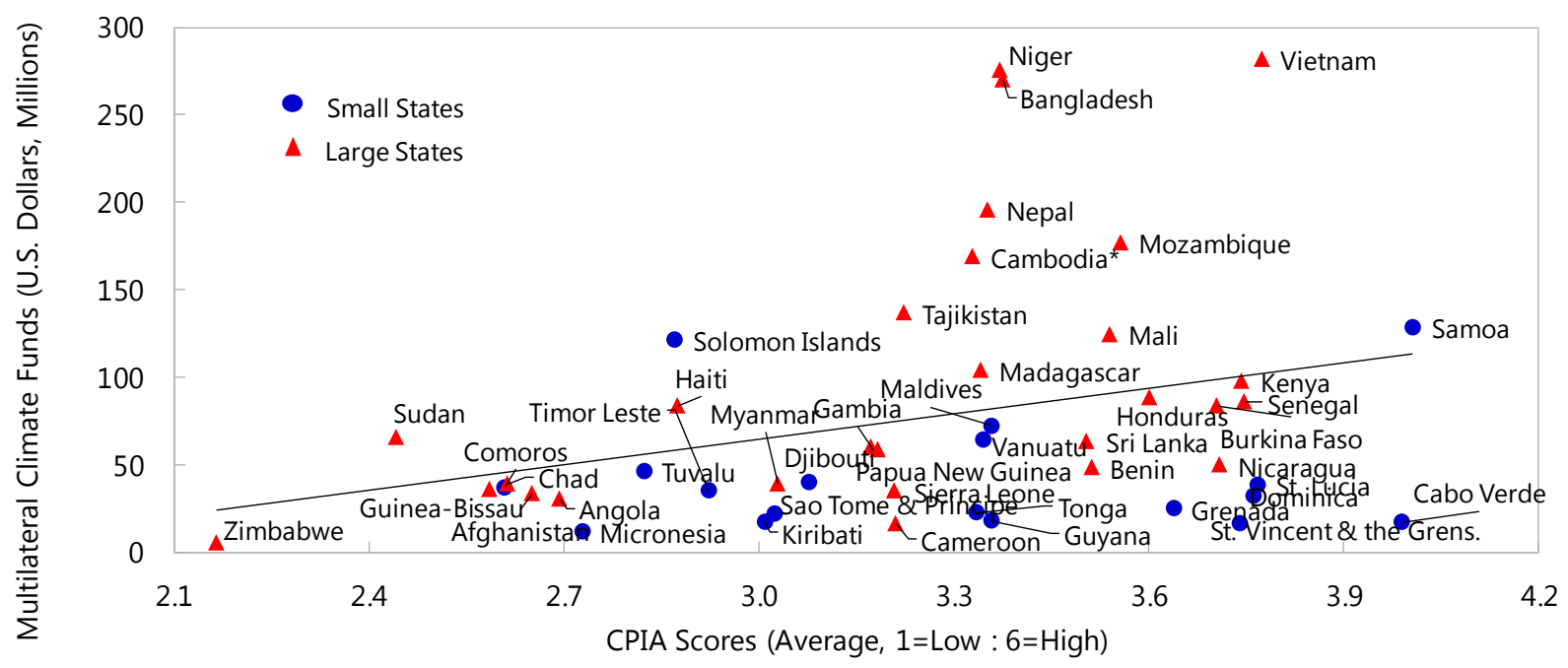

Sources: ODI Climate Finance Database; World Bank; and IMF staff estimates.

${ }^{1}$ CPIA data are not available for Antigua and Barbuda, Bahamas, Barbados, Belize, Chile, Costa Rica, Dominican Republic, El Salvador, Eswatini, Fiji, Guatemala, Indonesia, Jamaica, Mauritius, Palau, Philippines, St. Kitts and Nevis, and Trinidad \& Tobago.

of disaster risk and losses in lives, livelihoods and health and in the economic, physical, social, cultural and environmental assets of persons, businesses, communities and countries. 


\section{BUILDING RESILIENCE}

13. The components of a national DRS can be grouped into three complementary pillars: measures to improve structural resilience, financial resilience, and post-disaster resilience

(Figure 4). Improving structural resilience entails appropriately chosen and prioritized investments that limit the impact of disasters; ensuring financial resilience entails the use of fiscal buffers and pre-arranged financial instruments to manage recovery costs in the wake of a disaster; and postdisaster resilience requires contingency planning to support a speedy response to public needs in the aftermath of a disaster. The actions planned under each pillar need to be grounded on a strong diagnostic of the country's vulnerability to disaster risk and the quality of its preparedness and response mechanisms. ${ }^{4}$ They also need to fit within a coherent medium-term macroeconomic policy framework that ensures debt sustainability, supported by strengthened institutional and public financial management (PFM) arrangements.

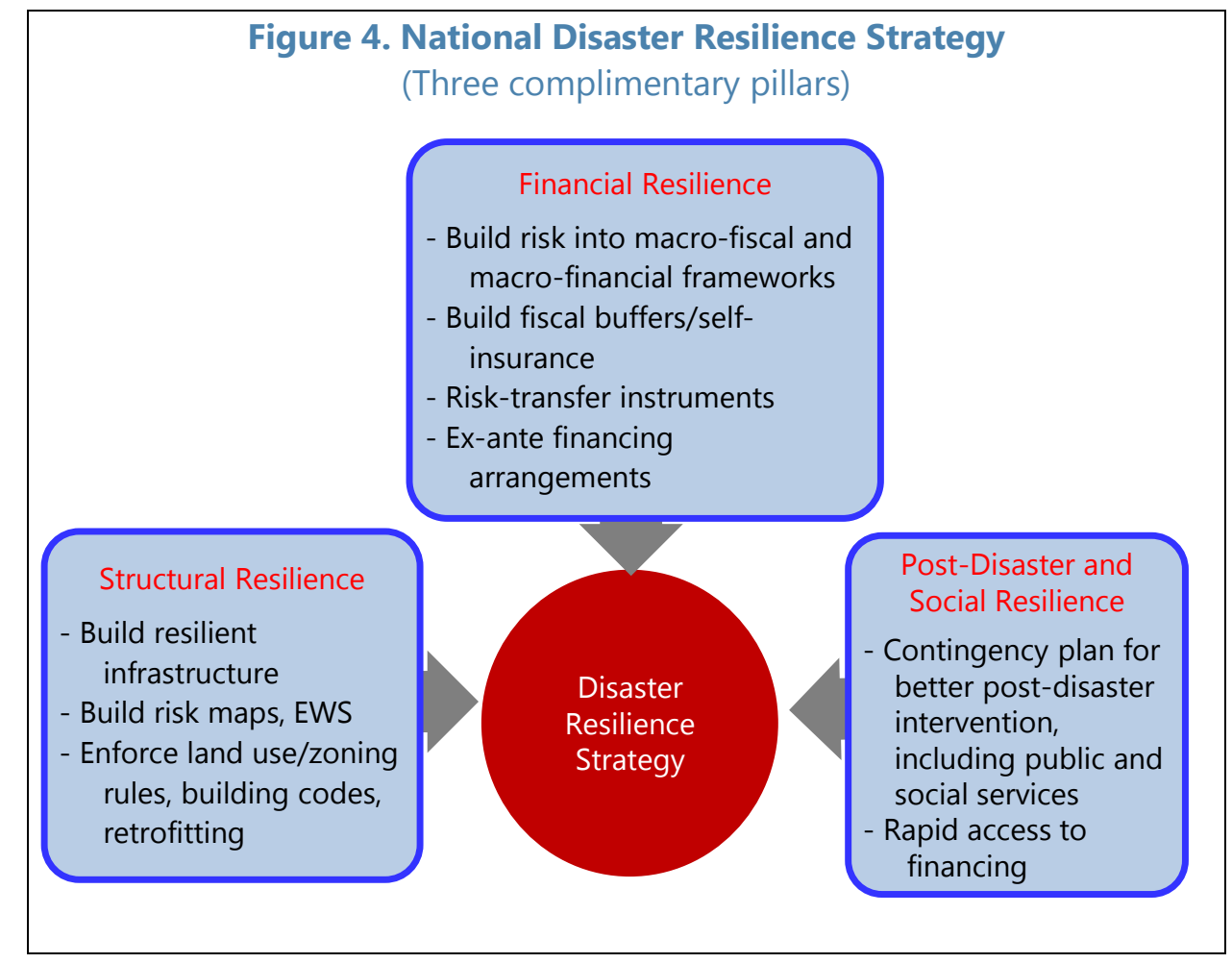

\section{A. Pillar I: Structural Resilience}

14. In disaster-vulnerable countries, investing in structural resilience should be a high priority. Such investment includes both "hard" policy measures (e.g., upgrading infrastructure, developing irrigation systems) and "soft" measures (e.g., developing early warning systems, customizing building codes and zoning rules). In many disaster-vulnerable countries, these

\footnotetext{
${ }^{4}$ This diagnostic should be seen as the foundation on which the three pillars are based: it incorporates the "risk identification" and assessment of "risk preparedness" components of the World Bank's framework, cited above.
} 
investments have taken a back seat to other urgent social and development needs, reflecting a combination of limited fiscal space, short time horizons for policymakers, and capacity constraints. As a result, efforts to build structural resilience, notably of public infrastructure and key economic sectors, remain well short of the scale that is called for. Moreover, in the absence of a comprehensive strategy to build resilience, investment in adaptation is often poorly coordinated and not sufficiently prioritized.

\section{The upfront cost of investing in structural resilience is significant but benefits that typically accrue over the medium to long run can exceed costs by a large margin.}

- Costs of building structural resilience. Priorities vary from country to country and so do the associated costs, but accurate estimates of the overall needs require full costing of investment plans (and their maintenance costs), which is often missing in disaster-vulnerable countries. This said, the required investments are likely to be significant relative to a vulnerable country's GDP and could far exceed its capacity to build meaningful resilience to climate change over the longer term. For example, according to UNEP (2016), the costs of adaptation to climate change in developing economies are currently estimated at about US\$56-73 billion, 2-3 times higher than currently available financing, and potentially rising to US\$140-300 billion by 2030 . For Fiji, adapting to climate change and natural disasters is estimated to require structural investments of around 100 percent of GDP over the next ten years, which-coupled with an increase in private investment-could be plausibly achieved by sustaining the public investment to GDP ratio at around 10 percent of GDP.

- The benefits of structural resilience. While costs are front-loaded, benefits usually accrue over many years, often well beyond the time horizon of governments seeking re-election. In addition to reducing expected losses from natural disasters, investing in structural resilience should raise returns to private investment, employment and output (thereby reducing outward migration), and facilitate continuous provision of public services. Such investment should also help reduce start-stop spending and protect the

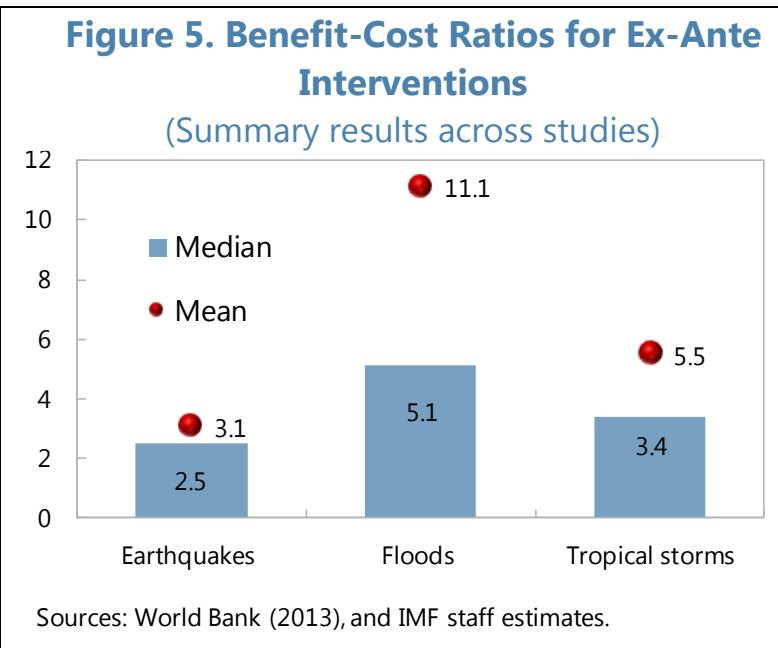
returns from other disaster-vulnerable development projects. Ultimately, resilient capital will also reduce the need for, and cost of, financial protection and ex-post assistance. For the countries in the ECCU, for example, staff estimates that public infrastructure resilient to natural disasters could increase potential output by 3-11 percent, with a growth dividend of 0.1-0.4 percentage points per year during the transition to the new steady state. Staff analysis for the Solomon Islands also shows that in addition to higher growth outcomes, public debt would be lower over the medium term from prioritizing resilient investment, strengthening public financial 
management and increasing public investment efficiency (see also Annex VI). According to a summary of microstudies by the World Bank, the benefit-cost ratio of investing in resilient infrastructure ranges from $\$ 2.5-\$ 11$ for every $\$ 1$ spent on resilient investment across various hazards (World Bank, 2013).

\section{Several vulnerable countries are making progress in building structural resilience} (Annex III). For instance, Fiji introduced a "build back better" campaign after cyclone Winston in 2016. Fiji and Tonga have made their electricity grids more disaster resilient, while Tuvalu has done the same for its docks. Madagascar, Malawi, and Mauritius have improved construction standards to better withstand storms, while Lesotho, Madagascar, and Mozambique have developed flood resistant infrastructure. Bank-Fund Climate Change Policy Assessments (CCPAs, Box 4), conducted so far for Belize, Seychelles, and St. Lucia, suggest that between one fourth and one third of the investment budgets in these countries are already devoted to resilience-building projects. Similarly, the World Bank's Climate Vulnerability Assessment (CVA) for Fiji, conducted in 2017, suggests that government spending on resilience grew fourfold over the preceding five years to about US\$170 million, and was about a tenth of the budget in FY2016/17. In Dominica, about half of the public investment since Hurricane Maria in 2017 has been allocated for disaster-resilient projects, in line with the government's goal to make Dominica the first disaster-resilient state. In Somalia, following recurrent drought, a recovery and resilience framework has been developed with the help of the UN and World Bank, and is being incorporated into their $9^{\text {th }}$ National Development Plan.

\section{Notwithstanding the progress, investment gaps in resilience building remain large.}

The three CCPAs noted above have estimated resilience investment gaps-the difference between required investment for building structural resilience and current investment levels-of 2-3 percent of GDP a year over a decade or more. Resilience gaps are also significant for some larger LICs: Ethiopia would have to more than double its current annual investments in climate adaptation (of US\$400 million or 0.5 percent of GDP) to fully implement the authorities' strategy for mitigating the impact of droughts on agriculture.

\section{The Way Forward}

18. Underinvestment in structural resilience reflects a mix of factors, including short-term bias in policymaking, tight fiscal constraints, and limits on borrowing capacity due to elevated debt levels or poor credit-worthiness; concessional financing from the international community is also limited.

- Policymakers need to make the case for additional investment, financed through a mix of measures to generate additional fiscal space (by improving revenue mobilization and/or prioritizing expenditures) and, in some circumstances, higher levels of external borrowing - with the appropriate mix depending on country conditions, including the outlook for debt sustainability (IMF, 2019).

- Additional aid flows targeted at key high-return projects are likely to be needed to ease the trade-off between fiscal adjustment and debt accumulation. In countries particularly exposed to 
large disasters, the scale of high-return resilience-building projects may be much larger than can realistically be financed through fiscal policy adjustments and prudent levels of commercial borrowing, implying that full implementation of the DRS will be feasible only if domestic efforts are complemented by significant new aid flows, whether from bilateral partners or multilateral institutions, including climate funds (Box 1).

\section{Box 1. Investing in Structural Resilience-Implications for Debt Sustainability and Concessional Financing}

Dominica was devastated by tropical storm Erika in 2015 and hurricane Maria in 2017, with estimated damages of near 100 percent and over 200 percent of GDP, respectively. High rehabilitation and reconstruction costs are compounded by costly resilient investment. With assistance from development partners, the government has developed a Public Sector Investment Plan, which includes resilient infrastructure projects. Incorporating the multi-year investment plan in the macro framework has implications for fiscal sustainability and for meeting the regional debt target of 60 percent of GDP by 2030.

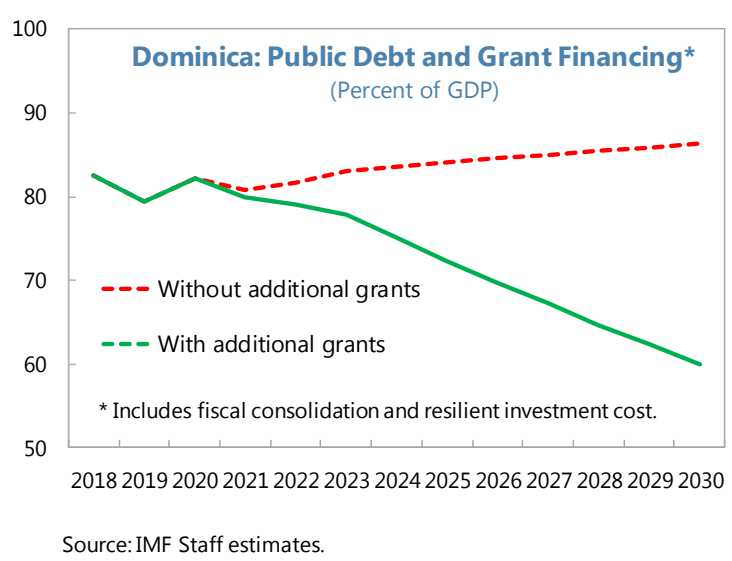

Staff assumes that to finance resilient investment the government can credibly (and at most) carry out additional fiscal adjustment of 4 percent of GDP, which is both back loaded (to allow output to first recover to pre-hurricane levels) and gradual. Given the additional fiscal adjustment, staff estimates that sustaining resilient investment will require an increase in grants of around 2.8 percent of GDP annually to meet the public debt target of 60 percent of GDP by 2030 , or about US $\$ 200$ million cumulatively.

Grenada has made important strides in preparedness for climate change, including developing a National Climate Change Policy and National Climate Adaptation Plan in 2017. It has also established a Ministry of Climate Resilience in 2017 to help mainstream climate change policies. A joint World Bank-IMF CCPA is also underway, which has identified a list of projects and a multi-year investment plan that would help build disaster resilience. Preliminary estimates indicate that public capital spending would need to be scaled up by 3 percent of GDP annually to implement all resilient investments by

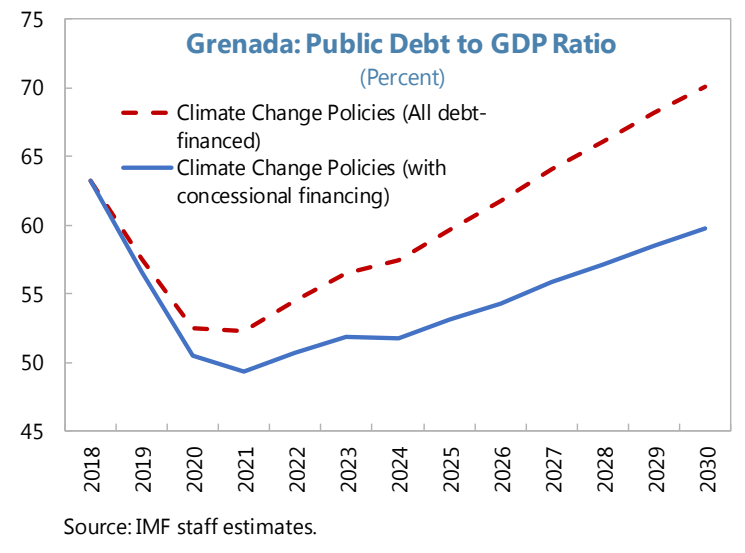
2030. To finance this, staff estimates that additional grant financing of US $\$ 15$ million annually (or US $\$ 185$ million in total) would be required for Grenada to stay within the regional public debt target of 60 percent of GDP. If such grants do not materialize, and the estimated increase in public investment is financed entirely by new borrowing, public debt as a share of GDP would rise to 70 percent by 2030 .

19. The private sector can play a useful role in supplementing public funding. For individual projects, the costs and benefits of private versus public solutions should be assessed by 
governments and private investment encouraged where it is economically and environmentally sustainable. Any contingent public sector liabilities, as with some PPP projects, need to be allowed for in comparing options, particularly in countries where capacity to negotiate sound PPP contracts is limited.

\section{Supporting investment in resilience can produce net savings for those bilateral donors that are likely to provide significant support for post-disaster recovery efforts. As examined in} Box 2, such investments reduce the costs of post-disaster recovery-and hence the ex-post financial support needed from donors. Realizing such a "win-win" outcome would require coordinated action by key donors to produce aggregate investment levels that yield large cuts in post-recovery costs. ${ }^{5}$

\section{Box 2. Savings from Ex-Ante Interventions ${ }^{1}$}

The benefits of ex-ante action for building resilience is assessed by using a dynamic stochastic general equilibrium model calibrated for six small states—Dominica, Antigua, St. Lucia, St. Vincent, Haiti and Fiji. These countries are assumed to be hit by various size disasters during a twenty-year period based on the historical frequency of these shocks. The following two policy options are assessed over this 20-year span:

- Option 1: Ex-post resilience investment. The government invests in resilient infrastructure only when public capital is damaged by natural disasters. Donors are assumed to cover the full cost of rebuilding after disasters, including the additional cost of resilient capital, which is assumed to be 10 percent more expensive than the non-resilient one.

- Option 2: Ex-ante resilient investment. The government maintains the same public capital stock as in option 1 in real terms but invests ex-ante in resilience building by replacing the depreciating capital fully with resilient capital every year. Because resilient infrastructure is more expensive, the government's nominal spending is 1 percent of GDP higher than it would have been without such ex-ante investment. It is assumed that donors finance this additional 1 percent of GDP a year, plus all post-disaster reconstruction as in option 1.

The cost of rebuilding is larger in the first option than the second as the stock of infrastructure is less resilient. The simulation suggests that the international community can save on average 10 percent of recipient's GDP across six countries, in net present value terms, by investing in ex-ante resilience and avoiding expensive rebuilding costs (left chart below). The savings would be less if the relative cost of resilient infrastructure is higher than the assumed 10 percent. In addition, the recipient countries benefit from better growth performance in the event of the disaster, with GDP on average 4 percent higher under ex-ante resilience building (right chart).

If the frequency of disasters increases due to climate change (in the simulation, there is one additional large natural disaster exceeding 20 percent of GDP damage in the 20 -year period), the benefits of ex-ante interventions are higher. Savings for donors would increase to 14 percent of recipient's GDP and the overall GDP level would be about 6 percent higher under ex-ante resilience building.

${ }^{1}$ Based on Wei Guo and Saad Quayyum "Building Resilience to Natural Disaster in Vulnerable States: Savings from Ex-Ante Interventions", forthcoming, IMF working paper.

\footnotetext{
${ }^{5}$ Each donor-supported resilience-building project, by reducing the costs of post-disaster recovery, generates a positive externality for other donors who are likely to provide support in the wake of a disaster.
} 


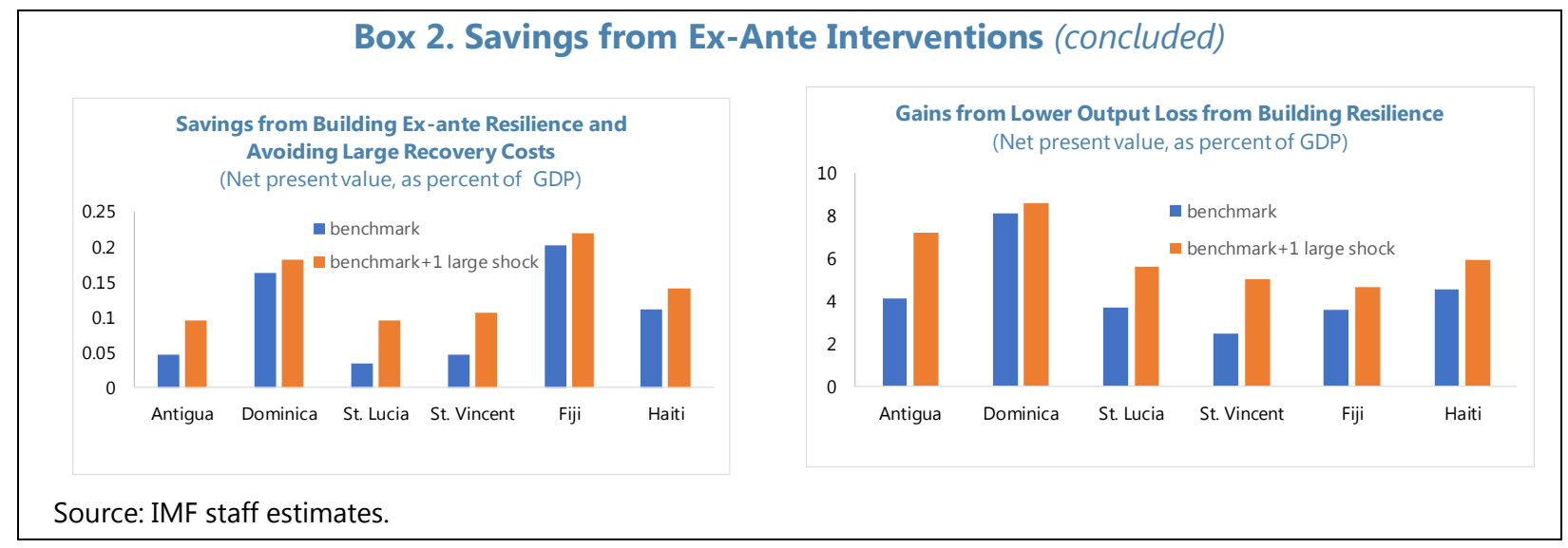

\section{B. Pillar II: Financial Resilience}

21. Strengthening resilience also requires policy action to manage the financial costs of natural disasters. Since the impact of disasters can be partially contained but not eliminated, disasters will still create sizable fiscal/financing shocks that need to be planned for. Absent planning, disaster-hit countries would encounter significant financing needs at a time when credit-worthiness has been adversely affected by the disaster, leaving the country with constrained and/or much more costly access to financing.

\section{Securing ex-ante financing for disaster costs through a multi-instrument strategy supports} better management of the fiscal and macroeconomic impacts of natural disasters. The World Bank's multi-layer risk approach—which combines different instruments for different layers of risk—provides a cost-effective approach for governments to address expected funding needs in the wake of disasters (Figure 6). Depending on the frequency and severity of disasters, governments may choose to manage their disaster risk by: (i) self-insurance through fiscal buffers; (ii) transferring risk through insurance or other risk-sharing mechanisms; (iii) arranging contingent financing via pre-arranged credit lines with IFIs; ${ }^{6}$ or (iv) reliance on concessional financing and humanitarian assistance from the international community when risk transfer is not cost effective for very large and rare disasters.

\section{Countries have pursued, to various degrees, such multi-instrument strategies. Several}

Caribbean countries are exploring or already have mechanisms to self-insure (e.g., the Bahamas, Dominica, Grenada, Jamaica, St. Kitts and Nevis, and St. Vincent and the Grenadines). In the Pacific Islands, five countries have considered pooling resources to form a regional savings fund. To provide immediate funding for emergency responses, the IDB and/or World Bank have contingent credit lines in Jamaica, Dominican Republic, Kenya and Seychelles, with several more in the pipeline; the ADB also has contingent financing lines for Pacific Islands (Cook Islands, Samoa, Tonga and Tuvalu). In addition, disaster-vulnerable countries have access to risk transfer through insurance, generally parametric, provided by regional pooling arrangements (Table 2). The Bank and IFC are supporting countries in the development of natural disasters and property insurance (including in Fiji).

\footnotetext{
${ }^{6}$ Examples include the World Bank's CAT DDO, the Inter-American Development Bank's contingent credit line (CCL) and facility (CCF), and the Asian Development Bank's Contingent Credit Line and contingent grants.
} 
Figure 6. World Bank's Multi-Layer Risk Approach to Financing Disaster Risk

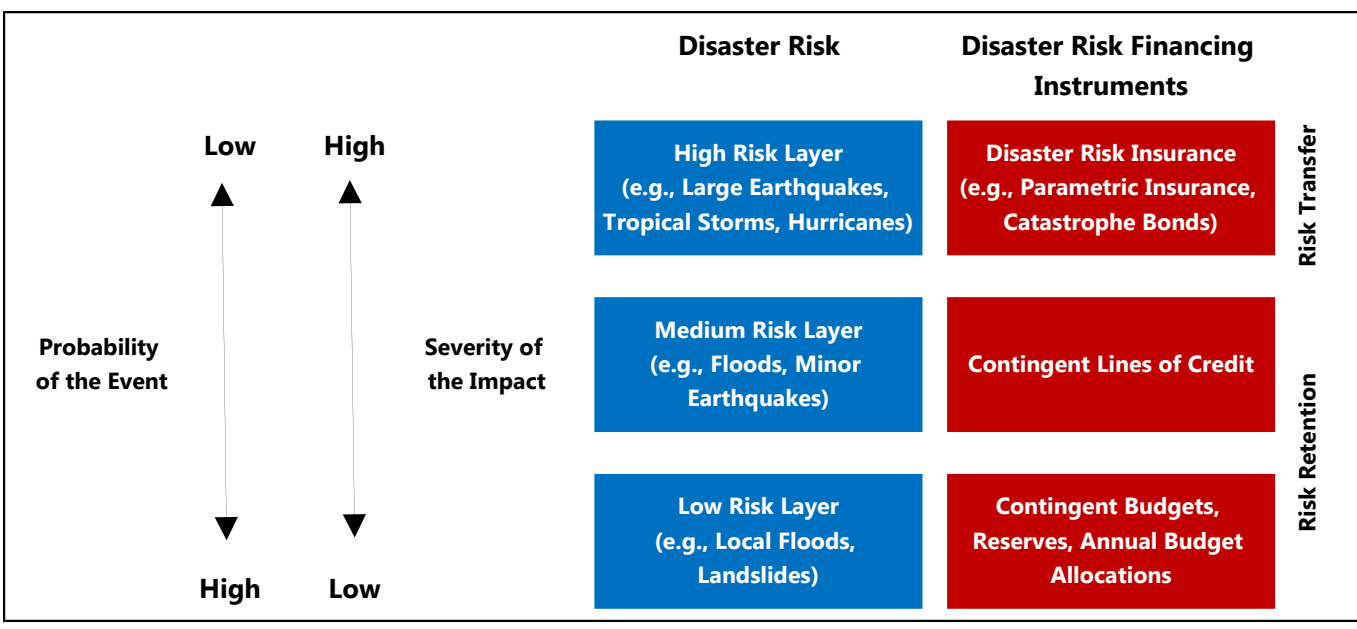

Source: World Bank.

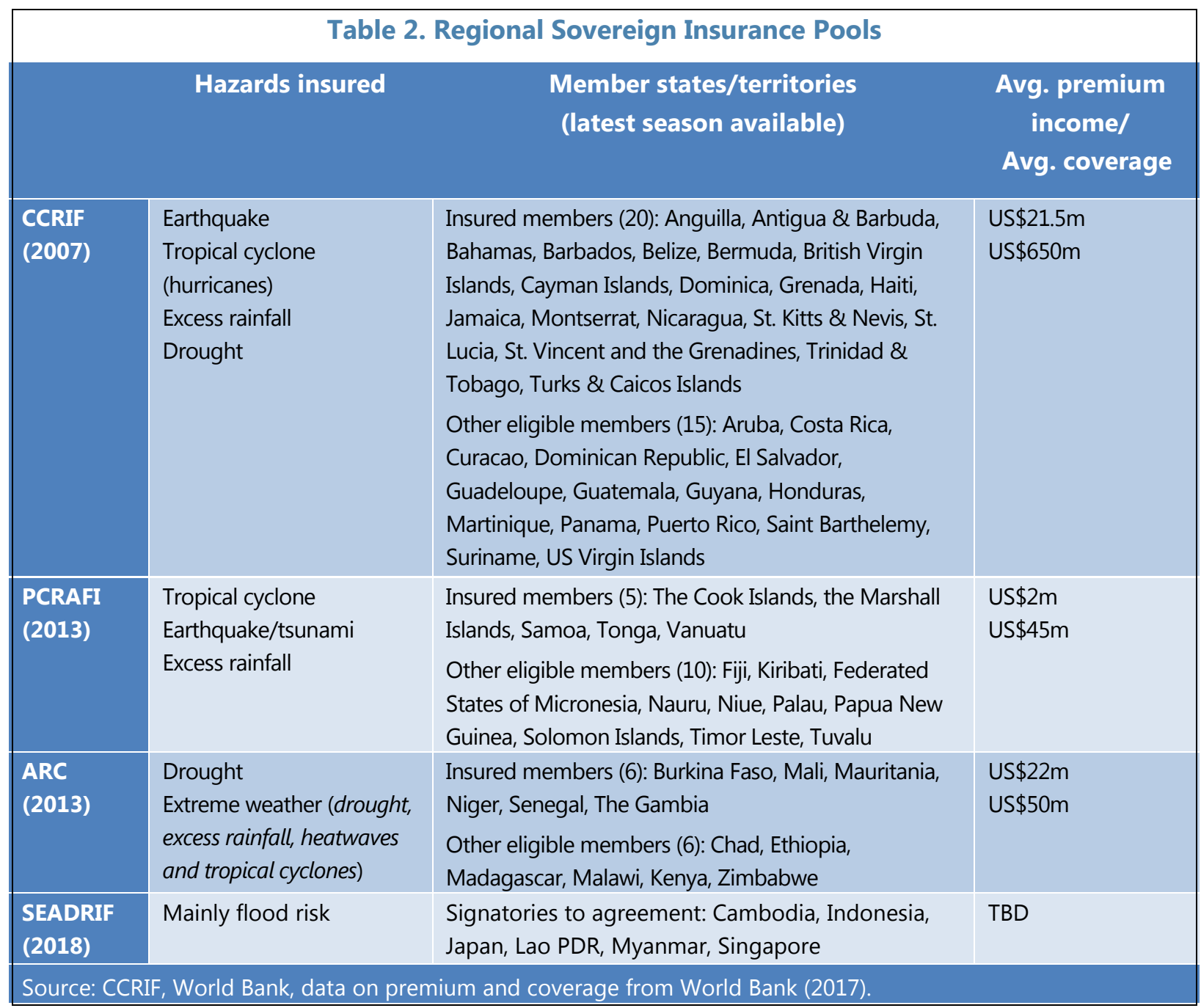


24. Despite the availability of these instruments, and their known benefits, their use has been limited due to cost and capacity constraints. Indeed, two thirds of the natural disaster losses in the Caribbean are uninsured, compared to about half in the rest of the world (Figure 7a).

- For sovereigns, weak fiscal positions, competing demands on public resources, and cost considerations typically limit their ability to self-insure or buy substantial disaster insurance. For instance, the cost of parametric insurance and catastrophe bonds (or "cat bonds", which are also based on parametric triggers; see Annex $\mathrm{I}$ ) is estimated to be in the range of 1.5-3.2 times the expected annual payout, reflecting a mix of factors, including large tail risks facing vulnerable countries (Figure 7b) geographical correlation of risks across potential buyers, and thin insurance markets facing small states. In addition, while sovereigns have relied on regional pools to reduce costs, these pools cannot fully cover very large losses because they have limits on maximum coverage and carry the risk that the payout would not be triggered or will be smaller than actual losses (the so-called basis risk).

- Private insurance penetration is also low, reflecting high premia, unfit construction that fails to meet insurability standards, and lack of social tradition of purchasing insurance.

Figure 7. Limited Risk Transfer through Insurance, and Losses from Natural Disasters

Panel A. Limited Risk Transfer through Insurance:

Large Share of Unisured Losses

(Meteorological loss events)
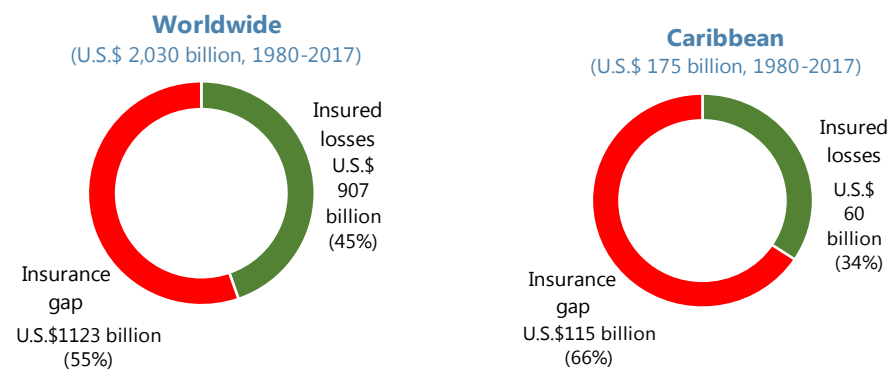

Sources: Munich RE; and IMF staff estimates.

Notes: Meteorological loss events include tropical cyclones, extratropical storms, convective storms, and local storms

Panel B. Losses from Natural Disasters

(Ex-ante loss for this country $=0.4 \%$ of GDP, but...)

There is this chance...

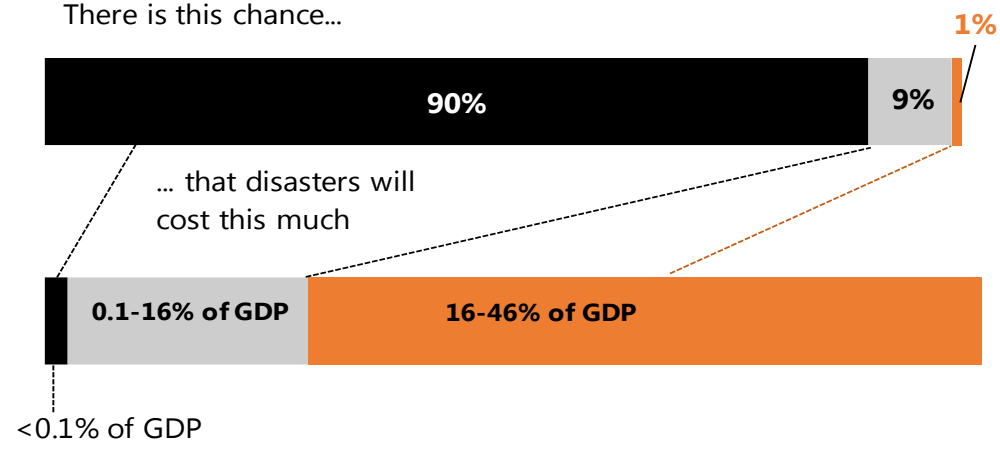

Sources: CCRIF data, and IMF staff estimates. 


\section{The Way Forward}

\section{In considering the choice of options, policy-makers need to take account of} country-specific factors and of how choices complement one other. In particular, to self-insure, countries need to decide how large their own fiscal buffers should be and how to build them (IMF, 2019). While building self-insurance funds - with strong institutional and governance arrangements - may be easier in countries benefiting from sizeable windfall revenues (such as from natural resource rents or "Citizenship by Investment" programs), most disaster-vulnerable countries will need sustained fiscal effort to build a fund of adequate size. For countries that decide to build such funds, at a minimum, the effort should aim at annual contributions into the savings funds equivalent to: (i) the expected value of annual damages from disasters (which could range upward from 0.4 percent of GDP for highly vulnerable countries); and/or (ii) the deductible under existing parametric insurance schemes. For many vulnerable countries, the high opportunity cost and capacity requirements of a fiscal savings fund argue for smaller funds and alternative arrangements, such as contingent financing.

\section{Initial approval of some of the contingent credit lines provided by IFIs' boards requires} demonstration of fiscal and debt sustainability. While many countries have successfully accessed the World Bank's CAT-DDO (e.g., Dominican Republic, Seychelles, and Kenya), approval of the instrument requires that countries have in place an adequate macroeconomic policy framework, including the policy adjustments needed to achieve fiscal and debt sustainability, which has been a challenging pre-condition for some Caribbean countries.

\section{Higher uptake of insurance products by sovereigns requires cognizance of the} trade-offs between the fiscal costs of insurance and its growth benefits. In particular, higher risk transfer would provide higher protection to growth by enabling a faster recovery but could impact

fiscal costs due to premium payments (Cebotari et al. forthcoming). Optimal financial protection requires considering these trade-offs, which differ across countries depending inter alia on risk preferences. Staff simulations of existing parametric insurance options under various disaster profiles allows optimal packages to be identified depending on country risk preferences. Prioritizing fiscal sustainability considerations may require choosing less costly insurance packages, associated with lower payouts, and thus less beneficial growth outcomes (gray and yellow insurance coverage in Figure 8). Prioritizing higher growth outcomes (e.g., for more severely exposed countries) may require choosing more
Figure 8. Choosing Optimal Risk Transfer: The Trade-offs (Each dot $=$ insurance package with different risk transfer) $1 /$

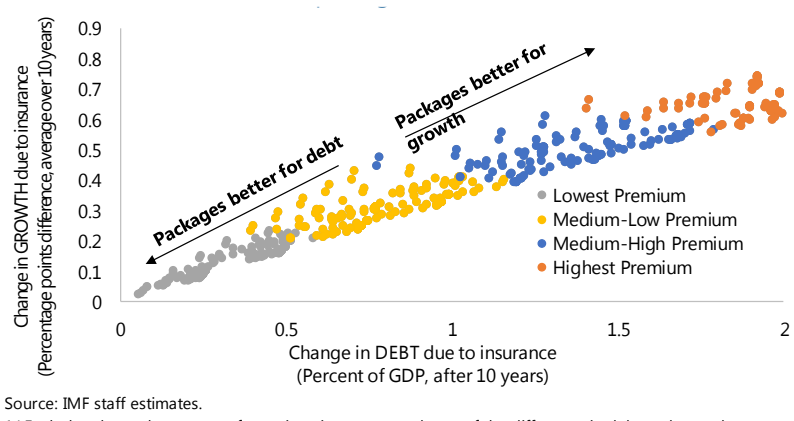

1/ Each dot shows the average, for a given insurance package, of the difference in debt and growth outcomes between insurance and no-insurance scenarios over 1,000 states of the world. 
expensive insurance packages, with higher payouts (orange and blue insurance packages). On balance, this trade-off is more difficult-and protecting growth is costlier-for severely-exposed countries; in such cases, focusing on fiscal considerations alone could result in suboptimal insurance choices in the absence of additional financial support (Annex V).

\section{Support from development partners could ease the fiscal constraints in choosing the} right level of insurance and enhance growth. Specific mechanisms include subsidizing insurance premia paid by countries either directly (e.g., by matching premia) or indirectly (e.g., by augmenting the capital of regional pools, thereby reducing reinsurance costs and allowing higher insurance coverage). The recent launch of the Global Risk Financing Facility(GRiF) by the World Bank, Germany, and the UK is a significant step in this direction.

\section{Additional ways to expand coverage of sovereign parametric insurance and reduce disaster costs include:}

- Diversifying risk further within and across regional pools. While regional pools are already working to diversify risks by expanding memberships and insured perils, pools could also share risks among themselves to reduce costs.

- Developing additional risk transfer tools. Subject to country demand, innovative parametric and indemnity insurance products could be developed. For example, the currently small cat bond market could be expanded-with support from the World Bank-to help countries build the necessary capacity to access such products. Likewise, state-contingent debt instruments could help expand the sovereign toolkit for risk transfer and preserve policy space when it is needed most (Box 3). Innovative indemnity-based insurance (under which payouts are proportional to the actual, rather than modeled, losses) could help expand existing coverage (which cannot be scaled indefinitely due to basis risk and insurance capital requirements) and could be offered by the regional pools directly or as aggregators of indemnity risk from national-level insurance contracts.

- Increased private insurance penetration can also help reduce the fiscal cost of disasters and implicit contingent liabilities for sovereigns. Possible solutions include: (i) regional pooling of private insurance risk; (ii) government-sponsored pools for natural disasters to overcome private insurance market failures; ${ }^{7}$ (iii) incentives to private providers of risk transfer instruments if market failures exist; (iv) strengthened local (re)insurance supervision and regulation; and (v) enhanced financial literacy.

\footnotetext{
${ }^{7}$ In advanced economies, such pools include the National Flood Insurance Program (US), Florida Hurricane Catastrophe Fund, California Earthquake Authority, and New Zealand's Earthquake Commission. In emerging markets, the Turkish Catastrophe Insurance Pool established in 2000 with World Bank assistance manages the compulsory earthquake insurance in the country, limiting the fiscal contingent liability.
} 
Box 3. A Case for Climate-Resilient Debt Instruments

Climate-resilient debt instruments may help disaster-vulnerable countries transfer risks in a more costeffective manner (IMF, 2017, has a fuller discussion of the role of SCDI instruments and how they fit within the existing financial risk-transfer toolkit). At the request of the ECCU, the staff of the IMF and the World Bank have explored two instrument design options that could complement ongoing efforts to build financial resilience. $^{1}$

The first option would embed "disaster-linked clauses" inside debt contracts, to allow for an automatic extension of debt service in the event of a natural disaster that meets specified parameters. The occurrence of a natural disaster that meets these parameters would result in deferral either of principal or interest payments or both on these debt instruments for a specified time period. This deferral would reduce gross financing needs in the event of a disaster, thus reducing the likelihood of countries needing to enter into costly debt restructurings and/or arrears. The implied risk of payment reprofiling would be borne by creditors, who could demand a compensatory yield premium; this could be addressed at least in part by making the maturity extension NPV-neutral for creditors (e.g., a coupon enhancement could be attached to the extended debt). A draft term sheet for such clauses has been prepared by the International Capital Market Association (ICMA) and Clifford Chance to facilitate use by interested sovereigns. ${ }^{2}$

There are significant "first-mover" obstacles to be overcome in introducing new debt with such featuresparticularly when the new issuers are likely to be small states with relatively thin investor bases. For the first debt issued, the debt service relief after a qualifying disaster would be modest, the reduced risk of default would be correspondingly modest, and buyers may need higher yields to compensate for having claims pushed back relative to others. Given this, faster progress may be possible:

- where the debtor has a relatively short maturity of external commercial debt, so that a large volume can be reissued with the clauses in a small period of time.

- via liability management operations by one or more sovereigns; this will require coordination among sovereigns (say in the Caribbean), and support from the international community.

- by bilateral official creditors adopting a standardized approach to embedding disaster-linked clauses in their own lending, thus ensuring equal treatment and fair burden-sharing across this creditor group. This issue is currently under review in the Paris Club.

- in debt restructurings, where all creditors would receive new debt instruments with disaster-linked clauses. Grenada 2015 and Barbados 2018 are two recent, susccessful examples of this.

The second option is akin to acquiring sovereign insurance against natural disasters, where countries purchase insurance to cover a specified amount of debt service payments following catastrophic disasters. Specifically, countries would take insurance cover from a private insurance company or a regional risk pooling mechanism, such as the CCRIF, for a "predefined set of debt obligations," including scheduled amortization, interest payments, or both. The precise structure and coverage could be tailored to the country's specific needs. If a disaster occurred, the country would be paid by the insurer the predetermined amount for servicing the debt. The corresponding payout would also reduce the stock of debt, as the debt service will not be financed by the country but by a payout provided by the insurance policy.

1 These options were discussed at the November 2018 high-level conference on Building Resilience to Natural Disasters and Climate Change in the Caribbean.

${ }^{2}$ The draft term sheet is at https://www.icmagroup.org/resources/Sovereign-Debt-Information/ 
Box 3. A Case for Climate-Resilient Debt Instruments (concluded)

This option has merits, as it is broad and not limited to a specific type of debt, potentially applying to all new and existing debt (though cost savings, in the form of lower interest rates, are likely to be larger if insurance is acquired on debt to be issued). The cost of buying such insurance could be at the lower end of the insurance pricing spectrum, since the amount of the payout is predetermined, and could be further trimmed if risks are pooled across countries.

But there are also drawbacks to this approach. As with any insurance, it requires countries, many with constrained fiscal positions, to finance ex-ante premia for an uncertain return; with underdeveloped and thin insurance markets, the costs of such insurance relative to expected return could be high. And tying insurance to debt service payments, rather than seeking untied disaster insurance, is likely warranted only if it is expected to produce significantly lower coupon rates on new issues and/or strengthen the sovereign's ability to maintain market access in the aftermath of a disaster.

\section{As noted earlier, building resilience via the mechanisms discussed under pillars I and} II constitutes a meaningful strategy only if it is embedded in a realistic macroeconomic framework that is consistent with maintaining a sustainable debt position. Staff analyses of building disaster resilience in the Caribbean and Pacific Islands provide illustrations of how this can be done (Annex VI).

\section{Pillar III: Post-Disaster Resilience}

31. While scaling up structural and financial resilience building may take time, early action is warranted to develop a detailed action plan to guide the response of government agencies and the wider public in the wake of a disaster. Such an emergency response plan (i.e., disaster recovery framework) would clarify institutional arrangements, responsibilities, and the post-disaster decisionmaking process in order to strengthen the ability to rapidly mobilize financial and physical resources to contain disruption to public services including water, electricity, medical services, schools, citizen security, and critical financial services.

\section{Existing social protection systems can be an important instrument in facilitating a speedy} response to humanitarian needs in the wake of a disaster. Providing support to the segments of the population severely hit by a disaster without established mechanisms for providing social protection is likely to be delayed, poorly targeted, and vulnerable to corruption abuse. By contrast, an established social protection system, including primary care networks, that can be scaled up in response to a disaster would lay the basis for a speedy response to address humanitarian needs in a more efficient manner. ${ }^{8}$ For example, Ethiopia's Productive Safety Net Program —an efficient and transparent government cash transfer program - has several features that make it easy to scale up as needed to address food insecurity and dispense aid.

33. The quality of public procurement systems also influences the government's response to a natural disaster. Technical support may be needed to ensure that there is adequate capacity in place to

\footnotetext{
${ }^{8}$ An assessment of social safety nets to calibrate their adequacy for disaster resilience can help identify gaps and shape necessary reforms ( $\$ 50)$.
} 
process supplies and procurement challenges linked to large aid inflows; weak procurement systems would undermine the effectiveness of the government's response to the disaster and deter donors from distributing assistance through existing government instruments and systems.

\section{Disaster-vulnerable countries have taken important steps to improve emergency}

preparedness. Most countries have enacted legislation, policies, platforms and coordination institutions for disaster risk management and early warning, with significant focus on regional expertise pooling:

- In the Caribbean, 18 countries have established a regional inter-governmental agency for coordination of emergency response to generate economies of scale and facilitate logistics more systematically (The Caribbean Disaster Emergency Management Agency, CDEMA). CDEMA's comprehensive disaster management strategy supports management of all phases of a disaster management cycle and is developing a regional risk information system to make information accessible to stakeholders and generate greater risk awareness and preparedness, as well as evidence-based decision making.

- In Central America, common institutions were created in the context of the regional Policy on Comprehensive Disaster Risk Management to coordinate the prevention, mitigation, preparation and response to natural disasters. These include the Coordination Center for the Prevention of Natural Disasters in Central America, which covers six countries.

- In the Pacific region, the Pacific Islands Emergency Management Alliance works with national and regional disaster agencies to strengthen a country's disaster response and has created a framework for national and regional agencies to work in partnership preparing, responding and recovering from a disaster. Likewise, the Pacific Catastrophe Information System has been created to enhance data collection and information sharing. Early warning systems have been successful in Vanuatu.

- In Africa, the Africa Regional Strategy for Disaster Reduction was adopted by the African Union in 2004. In line with the Sendai Framework in 2015, governments have committed to a revised Program for Action that strengthens efforts to increase resilience. While a coordinated approach to disaster risk reduction in SSA is still in development, with the Africa Risk Capacity Agency allowing for some coordination at the regional level, particularly in the Sahel, the EAC countries have been working on coordinating their efforts, and Indian Ocean countries share information regarding storms.

\section{The Way Forward}

\section{Despite the progress noted, many disaster-vulnerable countries face constraints in} developing ex-ante preparedness to natural disasters. Logistical capacities (e.g. evacuations, providing effective relief), remain relatively limited. The pooling of regional expertise is a welcome approach which could be further developed to provide economies of scale. Opportunities for peer-learning and sharing of resources across countries should be further fostered. There are also policies and strategies which have been successfully adopted in other emerging and advanced economies exposed to natural disasters that can be deployed in smaller economies (e.g., Indonesia, Philippines, Japan and New Zealand; see Annex 
VII). Targeted support from development partners to help disaster response planning and minimize disruption to public and social services can also yield high returns.

\section{TOWARD A FRAMEWORK FOR ENHANCED COORDINATED ACTION}

\section{A. The Case for Enhanced Coordination}

36. There are numerous stakeholders that seek to help disaster-vulnerable countries build resilience to natural disasters. This includes the Bretton Woods Institutions, the regional development banks, and bilateral development partners; the climate funds and private insurance companies also offer products that can be used to support resilience-building efforts. States with strong institutional capacity can develop national strategies that make effective use of the instruments and support provided by these institutions; states with weak institutional capacity are severely constrained in their ability to produce a coherent strategy that takes full advantage of the various forms of support available.

\section{The fragmented nature of current practices for provision of external support has been} highlighted by Caribbean and Pacific Island authorities. At the recent high-level conference on building resilience in the Caribbean, several leaders voiced their support for "building an alliance" or a "grand bargain" among key stakeholders for coordinated and specific actions to support investment in disaster resilience. This is an ambitious objective, highlighting the frustration with the existing architecture, but previous experiences with stakeholder coordination, as in the provision of debt relief for poor countries, point to the potential for coordination, as well as lessons on what works well and what does not. The PFTAC $25^{\text {th }}$ anniversary event, held in December 2018, also underscored the need for a coherent medium-term approach to help countries prioritize and prepare for natural disasters and noted the complexities of dealing with multiple agencies with differing criteria and requirements.

38. In addition, the current strategies do not fully develop the macro-fiscal aspects of disaster resilience. The national strategies for disaster risk management developed with support from IFIs generally do not fully integrate fiscal and debt sustainability aspects into the macroeconomic framework, which is needed to fully understand the economic trade-offs.

39. The remainder of this section outlines a proposed framework for facilitating effective coordination across development partners in supporting resilience-building efforts. The framework takes account of capacity limitations at the national level, while seeking to make effective use of the specialist expertise of the various development agencies.

\section{B. Developing A Disaster Resilience Strategy}

40. The key building block for coordinated support would be a country-owned DRS, identifying the main policy actions needed across the three pillars. 
- As noted above, the DRS would need to be grounded on a comprehensive forward-looking diagnostic of the country's vulnerability to natural disasters and the adequacy of existing preparedness. The diagnostic would identify the key projects for inclusion in the investment plan; flag the shortfalls in the current (perhaps implicit) disaster financing strategy; and review the adequacy of the existing systems for post-disaster response.

- The DRS is a shorthand-term for a comprehensive country-owned resilience-building strategy, in which support to be provided by development partners is clearly identified: it would build on, rather than displace, existing resilience-building plans and strategies and should be aligned with the wider national development strategy.

- Many small countries have already embarked on measures to build resilience to disasters (e.g., Fiji, Jamaica, St. Lucia), with support from the World Bank and other MDBs. ${ }^{9}$ These measures are an important step forward but may tackle only selected elements of the required three-pillar strategy; the frustrations of country authorities with the fragmented nature of external support suggests that more is needed to address coordination issues.

\section{Substantial additional support and engagement from development partners would be needed to help disaster-vulnerable countries flesh out and implement a DRS. ${ }^{10}$ For example,}

- Development of a well-grounded diagnostic would require substantial external assistance. A valuable tool in this context could be a Climate Change Policy Assessment (CCPA), an instrument currently being piloted in a handful of small island developing states by the IMF, with extensive support from World Bank staff (see Box 4), although the CCPA would need to be supplemented by other analysis and project costing to provide a full diagnostic.

- Technical support would be needed to identify and to cost the key projects needed to build structural resilience, drawing on development partners with the relevant expertise.

- An evaluation of the country's strategy for managing disaster financing, and how it could be enhanced, would need to be provided by external experts-either the IFIs or through technical assistance from bilateral development partners.

- Support for developing a medium-term macroeconomic framework that incorporates the required investments and adjustments in financing strategies could be provided in the context of IMF surveillance activities.

- Engagement with the climate funds to tap into financial support for adaptation to climate change would likely need support from both development partners and from peer-learning and pooling of experiences.

\footnotetext{
${ }^{9}$ For example, several countries have been implementing DRM/DRFI strategies with World Bank support.

10 Development partners are already providing support to several disaster-vulnerable countries in a number of the areas cited.
} 


\section{Box 4. The Climate Change Policy Assessment}

The Climate Change Policy Assessment (CCPA) is a tool developed by Fund and Bank staff (see IMF, 2016a) to help small states analyze and develop a policy response to the expected economic impact of climate change, and natural disasters arising thereof. The CCPA includes an assessment of projected economic impact, a costing of the planned policy response, and recommendations on fiscal and structural reforms to strengthen national strategies.

\section{The questions addressed by the CCPA include:}

- Climate change risks and expected impact. How vulnerable is the economy to climate change and what impact is climate change likely to have on long-term economic sustainability?

- General preparedness. How well-prepared is the country to cope with more intensified disaster shocks? Is the climate response strategy consistent with broader development goals?

- Mitigation commitments and strategy. How does the country plan to meet its greenhouse gas emission reduction targets? Does the current tax and subsidy system deliver appropriate carbon pricing and how could it be reconfigured to enhance its effectiveness?

- Adaptation needs and plans. Has the country an appropriate strategy to adapt to climate change? What key elements are missing from current plans? Do regulations, including zoning, provide the right support for adaptation efforts?

- Financing strategy for mitigation and adaptation programs. Does the country have adequate financing to implement its climate change strategy? Is the financing of the strategy consistent with maintaining fiscal and external debt sustainability?

- Risk management strategy. Does the government self-insure against risks? Does it make sufficient use of risk-transfer mechanisms, including insurance and pooling arrangements? What more should be done?

- National processes. Have climate-related projects been integrated into national plans? Are adequate public financial management systems in place to ensure climate-related investments will be executed efficiently?

The CCPA provides a useful framework for identifying policy gaps and capacity constraints; prioritizing and sequencing projects, financing, and capacity-building needs; strengthening coordination across government ministries; and coordinating TA by the Fund and the Bank, based on their respective areas of expertise. To provide a proper diagnostic for a DRS, it would need to be re-oriented to focus on current and near-term disaster risks, both climate-related and other risks.

Since 2017, CCPA pilots have been completed for Seychelles, St Lucia, and Belize; a CCPA is in progress for Grenada and planned for Micronesia and Tonga. Extending use of the CCPA to other countries would require: (i) assessing the lessons from the pilot process and deciding, in conjunction with the Bank, to broaden use of the CCPA beyond the pilot stage; (ii) agreement on formalizing Bank participation in producing CCPAs; and (iii) finding the additional budgetary resources needed, recognizing that not all vulnerable countries are currently committed to developing a comprehensive climate response strategy.

- For many small/low income countries, domestic efforts to generate fiscal space for a comprehensive DRS are unlikely to be sufficient: additional external concessional support for a comprehensive plan will likely be needed to avoid threatening debt sustainability.

\section{The adoption of a DRS (or its equivalent) supported by multiple development partners, including IFIs, should have a strong catalytic effect in terms of mobilizing donor support. A critical}


mass of partner support would enhance the credibility of the government's strategy; endorsement of individual components of the strategy by development partners, including Fund endorsement of the associated macroeconomic framework, would provide confidence to private markets and other potential partners that the strategy is viable and warrants support.

\section{A Potential Division of Labor Across Stakeholders}

\section{An agreed framework that identifies the role of the various development partners in supporting development of a DRS would help avoid duplication and create synergies. A} country's interest in developing a DRS would be the starting point for providing technical assistance; once fleshed out, the DRS would be based on a country-owned plan around which coordinated support can be provided. In this regard, the authorities of Dominica and Grenada have expressed strong interest in collaborating with development partners to develop a DRS.

- Drawing upon available diagnostic tools, the World Bank and other development banks could take the lead in helping the country identify and assess disaster vulnerabilities and prioritizing investment needs, based on a Bank-Fund CCPA or alternative diagnostics. They could also contribute to providing unified policy advice on financial resilience, including through technical assistance to help design and operationalize disaster risk finance strategies and make available contingent financial support; and provide technical assistance in building post-disaster and social resilience (such as social safety net design).

- The Fund could take the lead in helping the country develop a macroeconomic policy framework that adequately reflects both disaster costs and returns from resilient investment; identify fiscal actions, including domestic revenue mobilization and expenditure management, to support the policy framework; contribute to unified policy advice on financial resilience, focused on the mix of market insurance versus self-protection through fiscal buffers or use of climate-resilient debt instruments; provide balance of payments support, either via an arrangement (precautionary or disbursing) or post-disaster assistance; and deliver targeted capacity building support.

- In addition to helping countries elaborate the DRS, bilateral development partners could supply technical assistance for building disaster preparedness; provide concessional financing for projects or the budget in support of resilience-building investments; help alleviate insurance costs as a key component of the country's financial resilience strategy; and work with country authorities to prepare project proposals for financing by climate funds.

- Climate Funds could consider the DRS and the IFIs' endorsement of resilience building efforts and macroeconomic policies as a screening device to allow simplification of administrative requirements and criteria for qualification to provide financing for identified projects.

- Official sector insurance companies, such as CCRIF, could work with the IFIs to help design the country's financial resilience strategy. 
44. The division of labor discussed here is illustrative in nature. Fleshing out general principles would require further discussions with the various potential actors, while the division of labor in an individual country would depend on country circumstances and the various agencies' prior engagement in the country.

\section{THE FUND'S ROLE IN BUILDING RESILIENCE}

45. The Fund can play an important role in supporting resilience building in disastervulnerable countries, in line with its mandate to analyze and advise on macro-critical issues and support associated capacity development. There is further scope for Fund surveillance to address the impact of natural disasters and the case for resilience building in disaster-vulnerable countries; to support implementation of countries' resilience building strategies through Fundsupported arrangements, with financing to meet balance of payments needs where justified; and to support development of domestic macro-fiscal analytical capacity and related institutions through its capacity-building activities. As described in the previous section, the Fund can help countries integrate the financing of resilience building into national macro-fiscal frameworks and assess fiscal sustainability in a context where the costs are upfront (which could worsen debt dynamics in the short term) while benefits accrue in the longer term. ${ }^{11} \mathrm{~A}$ sound macroeconomic analysis of longerterm debt dynamics may help reassure markets regarding fiscal and debt sustainability.

\section{A. Engagement in Fund Surveillance}

46. In disaster-vulnerable countries, country teams should highlight the risks of inaction in the face of disaster risk and analyze the returns to building structural and financial resilience. Where countries are implementing resilience-building strategies, the baseline macroeconomic framework and debt sustainability analyses should seek to incorporate both the costs and benefits of the investment strategy. The returns to potential resilience-building strategies can also be explored via a fleshed-out alternative macroeconomic framework and DSA.

47. The coverage of disaster risks and resilience-building in surveillance of disastervulnerable countries has increased significantly in the past few years. Various approaches have been adopted by country teams, partly reflecting data limitations and country-specific features.

- A wide range of options are provided in IMF (2016a) for incorporating the impact of natural disasters in the macroeconomic framework. Based on a review of Article IV staff reports during 2017-2018 and a survey of country teams, many desks included disaster costs in baseline projections-with some country teams developing innovative methodologies to achieve this (e.g., for the Pacific Islands, see Lee, Zhang and Nguyen (2018) (Box 5), and for Dominica see 2018 Article IV).

\footnotetext{
${ }^{11}$ There is a close analogy here with analyzing the effects of scaling-up public investment in developing countries.
} 


\section{Box 5. Integrating the Cost of Natural Disasters in the Pacific Islands}

Staff investigated the impact of natural disasters in Pacific Island Countries (Lee, Zhang, and Nguyen, 2018). The paper highlights the intensity of natural disasters for each country in the Pacific based on the distribution of damage and population affected by disasters and estimates the impact of disasters on economic growth and international trade using a panel regression. The results show that severe disasters have a significant and negative impact on economic growth and lead to a deterioration of the fiscal and trade balances. The paper then identifies a simple and consistent method to adjust staff's economic projections and debt sustainability analysis for disaster shocks.

Probability of Severe Natural Disasters in PICs

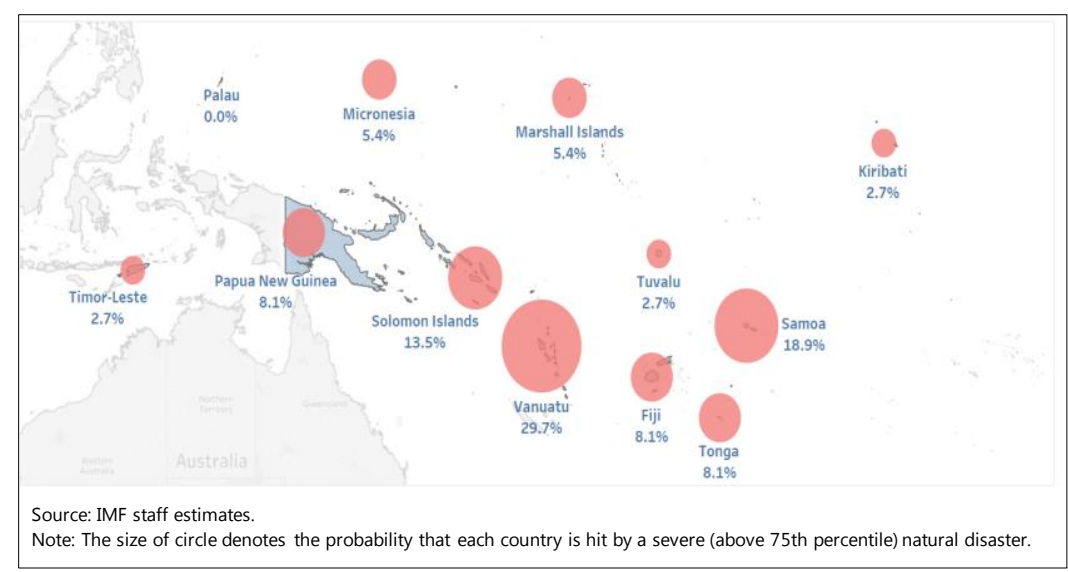

Staff explicitly adjust their long-term baseline projections in line with the expected impact of disasters for the region times the probability of a disaster occurring in their specific country each year, subtracting this from a non-disaster projection. The projections vary given the vulnerability of a country to natural disasters-adjustments range from 0.2 percent of GDP up to 0.6-0.7 percent of GDP per year and are largest for Vanuatu, Samoa, Solomon Islands and Tonga for which the recent Article IV reports adopted this approach. Staff reports have also discussed ways in which to help build fiscal resilience to shocks.

Further work is now looking at fiscal balances in Pacific countries using a similar cross-country panel regression methodology (Nishizawa et al, forthcoming). This information is helpful to estimate potential fiscal buffers needed to cover budget shortfalls because of natural disasters and provides input for the DSA of natural disaster scenarios. Staff have also looked at aid uncertainty. In the Pacific, international financial support following disasters has varied widely and unpredictably from 1.7 to 18.5 percent of GDP in recent years. Such uncertainty makes it exceptionally difficult for vulnerable countries to plan the appropriate level of fiscal buffers or lines of credit needed to finance disaster recovery.

This work is aimed at helping countries better incorporate the economic impact of natural disasters into their budget and consider the types of financing needed. Like the Caribbean, insurance has been inadequate in the Pacific at the national and regional level and private insurance markets are largely missing for households and firms. Efforts are being made by different IFIs and bilateral development partners but there is scope to more closely coordinate and scale up these efforts. 
- Several country teams have incorporated the impact of natural disasters as a shock to the baseline macroeconomic framework, typically via the debt sustainability assessment. Including a natural disaster shock is now a required scenario for disaster-vulnerable countries in the new LIC Debt Sustainability Framework and is being considered as one of the tail shocks in the ongoing MAC-DSA review.

- Debt sustainability analysis could be augmented to include the costs and benefits of countries securing insurance, by simulating debt paths under various disaster shocks and identifying optimal risk transfer options (see $\llbracket 27$ and Annex V). Such an analysis can also be integrated with the World Bank's multi-layer approach to financial protection.

- The longer-term benefits of resilience investment have often been overlooked in assessments of debt sustainability, thereby overstating the scale of future debt burdens. ${ }^{12}$ In part to counteract this bias, the 2018 Article IV Consultation with the ECCU developed a scenario and associated debt dynamics that allowed for the policy efforts, costs, and benefits of building resilience; the benefits were also assessed in the Solomon Islands and Vanuatu Article IV consultations (Annex VI).

- The Fund's methodology for assessing external positions has been updated to include analysis as to how natural disasters affect the external balance and real exchange rates (IMF, 2019).

\section{B. Support via the Fund's Lending Toolkit}

48. Building resilience to natural disasters is a medium-term endeavor that the Fund can support most effectively through medium-term program engagement with member countries. Anchoring a Fund arrangement on support of a medium-term resilience building strategy would be appropriate where natural disaster risk is macro-critical.

\section{The existing Fund lending toolkit provides a range of options to support implementation of member countries' development strategies. The available options include:}

- A disbursing arrangement for countries facing balance of payments needs in implementing their resilience-focused medium-term program.

- A precautionary three-year SBA, for countries with potential BOP needs, as an insurance against an adverse shock (whether disaster-related or other) while implementing their Fund-supported program. ${ }^{13}$

\footnotetext{
${ }^{12}$ It is also important to ensure that the returns to resilience building are not over-stated-which has occurred on occasion in analysis of the scaling up of public investment in low income countries (LICs).

${ }^{13}$ The only concessional facility that is designed for use on a precautionary basis is the SCF, which currently has a maximum length of two years; the maximum length of the SCF is being reassessed in the context of the ongoing LIC Facilities Review.

(continued)
} 
- A non-financial signaling instrument (the Policy Coordination or Policy Support Instruments), for countries seeking to signal Fund endorsement of their economic program, which could facilitate access to Fund resources in case of a BoP need from an adverse shock.

- Post-disaster financial assistance via the RFI or RCF, to assist countries with an urgent BOP need when hit by adverse exogenous shocks such as a natural disaster. ${ }^{14}$

\section{Fund-supported programs could tailor program design toward supporting resilience}

building. The macroeconomic framework would suitably integrate the short-run costs and longer-term benefits of resilience investment. Structural conditionality would focus on priority actions in the resilience-building strategy, designed in consultation with the World Bank and other active development partners. Capacity-building support would be supplied, where needed, to help countries meet program objectives.

\section{Supporting Capacity Development}

\section{In most disaster-vulnerable countries, significant capacity development is likely to be} needed to implement the main components of a DRS. The World Bank has already been playing a key role in providing policy and technical assistance support across the three pillars of the DRS. The IMF has been helping countries integrate resilience-building plans into their fiscal frameworks, including through fiscal rules (Grenada and Jamaica). Under the proposed framework, close cooperation and coordination will be essential among multilaterals and other development partners to cover all the main elements of a DRS, provide consistent technical advice, and enhance absorptive capacity of the country.

52. On building structural resilience (Pillar I), the Fund can help strengthen countries' capacity to finance and manage efficiently the kind of large-scale infrastructure investment programs needed. In particular, the Fund could support:

- Developing medium-term fiscal and budgeting frameworks. Fund TA would help countries ensure consistency of infrastructure spending plans with domestic revenue and external financing prospects, prudent debt management, and the building of fiscal buffers.

- Strengthened domestic revenue mobilization. Fund TA on tax policy frameworks, legislation, and revenue administration, in the context of a Medium-Term Revenue Strategy, can play an important role is boosting revenue collections to fund resilience needs.

- Enhanced Public Financial Management (PFM). TA to build robust PFM systems will improve the returns on public outlays on resilient infrastructure while enhancing access to concessional financing. In the Pacific, for example, PFTAC has been working with the German development agency (GIZ) to ensure that PEFA assessments and reform roadmaps include measures that facilitate access to Climate Funds.

\footnotetext{
14 The LIC Facilities Review is considering the case for increasing access levels to the RCF (and, potentially, the RFI), including a higher cumulative limit for countries vulnerable to large natural disasters.
} 
- Robust public asset and investment management practice. A Public Investment Management Assessment (PIMA) can help institute strong public infrastructure procurement and management practices, boosting investment efficiency and enhancing access to external funding.

53. On building financial resilience (Pillar II), the Fund could support capacity development through:

- Building financial infrastructure and an understanding of risks and risk transfer. The Fund and the World Bank could support the setup of asset registries, risk management units, and supportive institutional and governance arrangements related to financial resilience choices. Likewise, TA on banking regulations and supervision could be deployed to ensure disaster vulnerabilities are fully allowed for in assessing risks to bank balance sheets.

- Using convening powers. The Fund and the World Bank, together with other international institutions, could use their convening power to help coordinate various stakeholders-private insurances, governments, regional pools, donors, climate funds-to resolve existing hurdles to accessing market-based risk transfer, including exploring the financial viability of debt instruments with disaster clauses and addressing scale obstacles to the development of insurance products. The World Bank has been very active in this space, as reflected in its lead role in the establishment of the Global Risk Financing Facility (GRiF) to scale up financial protection solutions.

54. On ex-ante preparedness for disaster recovery (Pillar III), the Fund role in supporting relevant capacity development role is limited. One area of engagement is promoting the development of business continuity plans for both the central bank and for commercial banks; PFTAC has held regional workshops to assist with the development of such plans. Assessing the resilience of banks' loan portfolios to disaster shocks is also part of building ex-ante preparedness: CARTAC workshops on stress testing of the financial system include tests of system vulnerability to hurricanes and other plausible disaster shocks.

\section{Capacity development efforts should involve close collaboration between providers,} while seeking to exploit similarities in the challenges across countries. Many of the capacity development issues relevant for resilience building do not fit neatly into the "traditional" areas of the various TA providers. Thus, a collaborative approach between institutions is essential to avoid overloading governments with limited absorptive capacity. Where challenges are similar across countries, scale economies can be realized using regional workshops and development of on-line courses. For example, regional workshops on medium-term fiscal frameworks and fiscal resilience to natural disasters were held in the Pacific by PFTAC, APD, and ICD in 2015 and 2017. 


\section{ISSUES FOR DISCUSSION}

\section{Directors' views are sought on the following issues:}

- Do Directors see the three-pillar strategy as a useful lens through which to view the challenges of building resilience in disaster-vulnerable countries?

- Do Directors see a compelling case for closer coordination among development partners in supporting resilience-building efforts in countries with insufficient institutional capacity to manage this coordination directly?

- Do Directors see a government-owned "Disaster Resilience Strategy" as a useful instrument for facilitating donor coordination?

- Do Directors agree that a DRS supported by key development partners could catalyze higher levels of concessional financing from bilateral donors, climate funds, and other financing sources?

- Do Directors see a need for Fund surveillance to give greater attention to resilience-building in disaster-vulnerable countries, recognizing that bilateral surveillance inevitably involves selectivity in regard to the topics covered?

- Do Directors agree that the Fund lending toolkit is broadly appropriate for supporting disastervulnerable countries that are implementing a resilience-building strategy?

- Do Directors see merit in the Fund, in collaboration with the Bank, conducting further work on the role of state-contingent debt instruments in disaster-vulnerable countries?

- The CCPA is still operating in a pilot phase. Do Directors see significant value-added for country authorities in the three CCPAs circulated to the Board so far? 


\section{References}

Asian Development Bank, 2018, "Economic and Fiscal Impacts of Disasters in the Pacific," (April).

Cantelmo, A., L. Bonato, G. Melina, and G. Salinas, 2019, "Policy Trade-Offs in Building Resilience to Natural Disasters: The Case of St. Lucia" IMF Working Paper No. 19/54 (Washington: International Monetary Fund).

Cebotari, A., I. Otker, and K. Youssef, forthcoming, "Natural Disaster Insurance for Sovereigns: Optimality and Affordability," IMF Working Paper (Washington: International Monetary Fund).

Cevik, S. and G. Huang, 2018, "How to Manage the Fiscal Costs of Natural Disasters," IMF How-To Notes No. 18/03 (Washington: International Monetary Fund).

Cummins, J.D. and O. Mahul, 2009, "Catastrophe Risk Financing in Developing Countries: Principles for Public Intervention," ISBN 978-0- 8213-7736-9 (Washington: World Bank).

Gamper, C., B. Signerii, L. Altonii, and M. Petrie, 2017, "Managing Disaster-Related Contingent Liabilities in Public Finance Frameworks," OECD Working Papers on Public Governance, No. 27, (Paris: OECD Publishing). Available on the internet: https://doi.org/10.1787/a6e0265a-en.

Ghesquiere F., and O. Mahul, 2010, "Financial Protection of the State Against Natural Disasters: A Primer," World Bank Policy Research Working Papers No. 5429 (Washington: World Bank).

Gurenko, E., 2004, "Catastrophe Risk and Reinsurance: A Country Risk Management Perspective," (London: Risk Books).

International Monetary Fund, 2016a, "Small States' Resilience to Natural Disasters and Climate ChangeRole for the IMF," IMF Policy Paper (Washington).

, 2016b, "Enhancing Resilience to Natural Disasters in Sub-Saharan Africa," in Regional Economic Outlook "Sub-Saharan Africa Multispeed Growth," October (Washington).

, 2017a, "Large Natural Disasters—Enhancing the Financial Safety Net for Developing Countries," IMF Policy Paper (Washington).

2017b, "State Contingent Debt Instruments for Sovereigns", IMF Policy Paper (Washington).

(Washington).

, 2018, "ECCU: 2018 Common Policies Discussion," IMF Staff Country Report

2018, "Sri Lanka: Selected Issues," IMF Staff Country Report No. 18/176

(Washington). 
2018, Dominica: 2018 Article IV Consultation" IMF Staff Country Report

(Washington).

, 2018, "Solomon Islands: Selected Issues", IMF Staff Country Report (Washington).

, 2019, "Fiscal Policies for Paris Climate Strategies: From Principle to Practice," IMF

Policy Paper (Washington).

International Panel on Climate Change Report, 2015, "Small Islands," Chapter 29.

International Red Cross, 2018, "Disaster Trends and IFRC Insights," in World Disasters Report 2018, ed. by

D. Fisher, K. Hagon, S. Swithern and L. Walmsley.

Lee, D., H. Zhang, and C. Nguyen, 2018, "The Economic Impact of Natural Disasters in Pacific Island Countries: Adaptation and Preparedness", IMF Working Paper No. 18/108 (Washington: International Monetary Fund).

Marto, R., C. Papageorgiou, and V. Klyuev, 2017, "Building Resilience to Natural Disasters: An Application to Small Developing States", IMF Working Paper No. 17/223 (Washington: International Monetary Fund).

Nishizawa, H., S. Roger, and H. Zhang, forthcoming, "Fiscal Buffers for Pacific Island Countries"

United Nations Environment Programme, 2016, "The Adaptation Finance Gap Report."

Werner, A. and K. Srinivasan, 2019, "How to Buffer the Caribbean from Financial Storms," Financial Times, Alphaville. Available on the internet: https:/ftalphaville.ft.com/2019/02/11/1549861202000/How-tobuffer-the-Caribbean-from-financial-storms/

World Bank, 2013, "Benefit-Cost Analysis for Risk Management: Summary of Selected Examples," Background paper for the World Development Report 2014 by Wethli, Kyla (Washington).

,2016, Confronting Drought in Africa's Drylands, edited by Rafaello Cervigni and Michael Morris (Washington).

World Bank Group, 2016, "Fiscal Disaster Risk Assessment and Risk Financing Options, Sri Lanka," (March). Available on the internet: https://openknowledge.worldbank.org/handle/10986/24689

,2017, "Sovereign Catastrophe Risk Pools: World Bank Technical Contribution to the G20" (Washington). Available on the internet: https://openknowledge.worldbank.org/handle/10986/28311

2018, "Climate Development Goals Through the Multiple Benefits of Disaster Risk Management" (Washington). 
2019, "Boosting Financial Resilience to Disaster Shocks Good Practices and New

Frontiers," World Bank Technical Contribution to the 2019 G20 Finance Ministers' and Central Bank Governors' Process (Washington). 


\section{Annex I. The World Bank Group's Support for Building Resilience}

1. The WBG has played a key role in providing support for adaptation and resilience to climate change. Over the past decade, the WBG, supported by the Global Facility for Disaster Reduction and Recovery (GFDRR) and its development partners, has mainstreamed disaster risk management into its operations. The Bank's annual funding of disaster risk management (DRM) projects has increased steadily over the past six years - from $\$ 3.7$ billion in fiscal year (FY) 2012 to $\$ 5.3$ billion in FY 2018. These projects were implemented across many sectors, including agriculture, environment and natural resources, transport, social protection, information and communications technology (ICT), and water.

2. The Bank gives special attention to small states, most of which are highly vulnerable to natural disasters and climate change. As an exception to regular IDA eligibility criteria, several small states (population less than 1.5 million) that are vulnerable to natural disasters are given access to concessional IDA resources. Total IDA lending to the 23 IDA-eligible small states increased from $\$ 604$ million in IDA15 to about $\$ 1.2$ billion in IDA17. The Bank also provides a platform to small states (Small States Forum) for high-level dialogue on how the WBG can help address their special development needs.

\section{Structural Resilience}

3. The WBG hosts several Funds that actively promote climate-resilient development. These include the Climate Investment Fund (CIF), the Forest Carbon Partnership Facility (FCPF), and the Global Environment Facility (GEF)/Adaptation Fund (AF) Secretariat.

\section{The CIF's Pilot Program for Climate Resilience (PPCR) has been one of the largest} financing sources of adaptation programs and projects with client countries. The program operates in partnership with other multilateral development banks (AfDB, ADB, EBRD, IDB, and WBG) to support adaptation in a coherent and integrated way. The World Bank has the largest PPCR portfolio, with 30 projects ( $\$ 490 \mathrm{~m}$ or about 40 percent of the total $\$ 1.2$ billion funding envelope) and takes responsibility for delivery of climate change resilience programs in the countries. The programmatic approach of the CIF's PPCR has proven integral to helping the WBG drive climate resilience action by developing a two-phased programmatic approach that mainstreams resilience in government agencies and provides risk-appropriate concessional financing for associated investments.

\section{Financial Resilience}

5. Through the Disaster Risk Financing and Insurance (DRFI) program, the WBG has supported more than 60 countries in developing and implementing financial protection strategies against climate and disaster shocks, including the development of regional sovereign catastrophe risk pools.

6. The WBG has also developed a series of innovative financing mechanisms. For instance, the Development Policy Loan with Catastrophe Deferred Drawdown Option (CAT-DDO) is a policy 
instrument to strengthen disaster risk management and financial preparedness, to support countries' recovery after disasters and enhance client government's resilience to shocks. To date, some 13 countries have benefitted from this instrument for a cumulative amount in excess of US $\$ 3$ billion. In addition, the World Bank has intermediated market-based risk transfer solutions such as catastrophe swaps and cat bonds for a cumulative amount in excess of US\$4 billion.

\section{The WBG is also managing new programs such as the Global Risk Financing Facility}

(GRiF), launched during the October 2018 Annual Meetings of the World Bank and International Monetary Fund. The GRiF aims to strengthen financial resilience of vulnerable countries by enabling earlier and more reliable response and recovery to climate and disaster shocks, and over time to a wider range of crises, through establishing and/or scaling up pre-arranged crisis risk financing instruments, including market-based instruments. It is delivered through a Multi-donor Trust Fund hosted by GFDRR and implemented by WB/DRFIP with expected donor contribution of US\$145M from Germany and UK with further contributions under discussion with other donors.

\section{Post-disaster Resilience}

\section{The WBG also offers a Contingent Emergency Response Component (CERC) under} investment project financing, which is a contingent line that does not require fiscal and debt sustainability for its approval. Given that investment project financing is about 60-70 percent of World Bank financing and is used in most countries, CERC is an important financial instrument that provides either quick disbursements following an event to finance critical emergency goods (e.g. imports, domestically-manufactured goods, etc.) or to finance emergency recovery and reconstruction works and associated services. The advantage of including a CERC in a standard investment lending operation is that it establishes an ex-ante mechanism which enables the recipient to rapidly begin to address their post-disaster needs. 


\section{Annex II. Natural Disasters in Sub-Saharan Africa}

\section{Floods and slow-moving disasters such as droughts account for $\mathbf{8 0}$ percent of loss of} life and $\mathbf{7 0}$ percent of recorded economic losses linked to natural hazards in SSA. Slow-moving disasters such as droughts and recurring weather-related epidemics can cause substantial economic disruptions, even if they lack the initial "shock and awe" associated with other disasters. Their slow onset creates the risk that the initial response is inadequate, while their persistence increases the risk of a prolonged impact (IMF 2016b). The full economic impact is usually not quantified or recorded. The cascading effects of a rapid onset hazard, such as flood or earthquake, can evolve into a public health emergency, as the health care system is overwhelmed, and displaced populations are concentrated in emergency camps. The squalid living conditions facilitate the transmission of diseases such as malaria and cholera.

\section{The $\mathbf{2 0 1 5 / 1 6}$ droughts in Southern Africa linked to El-Niño typified the large social} costs that slow-moving disasters can impose. Failed crops, depleted grain stocks, and de-herding represented a significant loss of income and savings for households. A lack of access to water and food contributed to malnutrition and missed schooling, highlighting the human costs, both in terms of deaths and deterioration of human capital. Many people above the poverty line temporarily dropped into poverty and malnutrition. Social tensions increased as people migrated to less affected regions and competition for grazing land among pastoral farmers rose.

3. The economic costs were also significant. Agricultural production was decimated in some of the most affected countries, leading to lower growth. Notwithstanding increased donor support, the fiscal situation deteriorated as governments scaled-up food distribution programs to mitigate the impact of the drought. The electricity supply was impacted by a shortage of hydro-power, hampering energy-intensive mining and manufacturing activities in several countries.

\section{The region's rising population, climate change, and latent vulnerabilities compound}

the risks. SSA's current population is projected to more than quadruple to nearly 3.7 billion by 2100, with 1 out of every 3 citizens on the planet being from the region (IMF, 2015). At the same time, the region is the least prepared to face the effects of climate change, including due to the heavy reliance on rain-fed agriculture, limited resources to foster resilience, and already elevated levels of poverty and food insecurity. Chart shows that SSA populations are highly exposed to droughts - with a quarter of the population affected on average during the worst droughts that countries experience after 2000. Given the rising intensity and unpredictability of such climatic events, building resilience is paramount

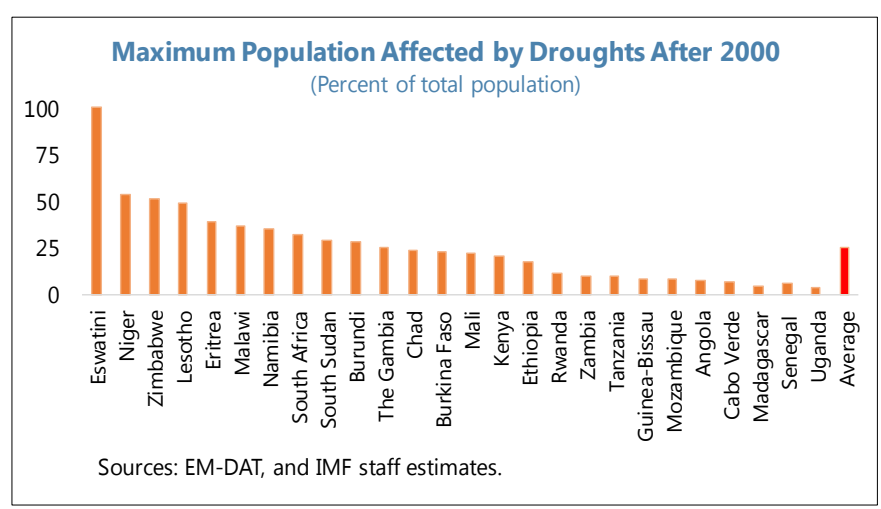




\section{Annex III. Policies to Enhance Resilience: Examples}

\section{Sub-Saharan Africa}

1. African countries have undertaken a range of policies to enhance their resilience and preparedness to natural disasters. Reflecting capacity and financing constraints, these policies, focused mostly on agriculture and infrastructure investment, tend to emphasize cost-effectiveness, mitigating the impact of natural disasters at a low cost. Many of these initiatives have been aided by new technologies and/or focused on the local level.

\section{Appropriately, agriculture has received significant attention given its economic} importance and vulnerability to drought ${ }^{1}$. Countries are trying new crop varieties that are more resilient to droughts and water stress. The harvesting of rain water at a local level also features prominently in country strategies. For instance, in Burkina Faso, large cisterns in sugarcane fields collect water that is distributed via efficient irrigation methods.

3. Leveraging technology is an important part of the resilience strategy. Several countries (including Ethiopia, Rwanda, Kenya) are using mobile technology to reach out to farmers with rainfall forecasts to optimize planting of crops and purchase crop insurance. Better coordination of information and associated logistical preparedness helped significantly in mitigating the social impact of the 2015 drought in Ethiopia through improved targeting of food delivery.

\section{Countries are also placing increased emphasis on disaster-resilient infrastructure,} which can be more expensive to build but offer higher returns in the long-run. As part of riskinformed planning, São Tomé and Príncipe and Zambia have moved people away from flood-prone areas. Kenya has diversified its energy generation away from drought-prone hydropower to include gas and geothermal.

\section{Fiji}

5. Fiji has stepped up efforts to build resilience to climate change. The government hosted the $23^{\text {rd }}$ Conference of the Parties to the UN Framework Convention on Climate Change, pledged to transition completely to renewable energy sources by 2030, and adopted a reforestation policy to store carbon. A "Build Back Safer" program was launched after the 2016 cyclone Winston with the aim of teaching residents to rebuild homes that are more resilient to natural disasters. The government is also looking at parametric insurance instruments to help households who cannot be insured or are "semi" insurable. They have established a Construction Implementation Unit to ensure reconstruction in the education and health sectors is done to higher resiliency standards. The findings of the 2017 Climate Vulnerability assessment are incorporated into the National

\footnotetext{
${ }^{1}$ Pre-disaster interventions to boost resilience can be cost-effective, especially compared to post-disaster relief. Dissemination of productivity-enhancing, resilient agricultural and herding techniques would cost about US $\$ 1$ billion in the Sahel and the Horn of Africa; humanitarian aid to the region totaled US\$4 billion in 2013 (World Bank 2016).
} 
Development Plan. Strengthening infrastructure is a priority in the strategy to adapt to climate change, with largest needs in the transport sector, investment in flood risk management, coastal protection measures, water and the energy sectors. Investments in education and health infrastructure are also required, as is enhanced asset and resource management. Private sector investment is being sought to help finance these needs. Fiji also issued a novel financing instrument-a sovereign Green Bond-on the London Stock Exchange in 2017, becoming the first developing country to undertake such an initiative. So far, the take-up of the bond has been mainly by domestic investors.

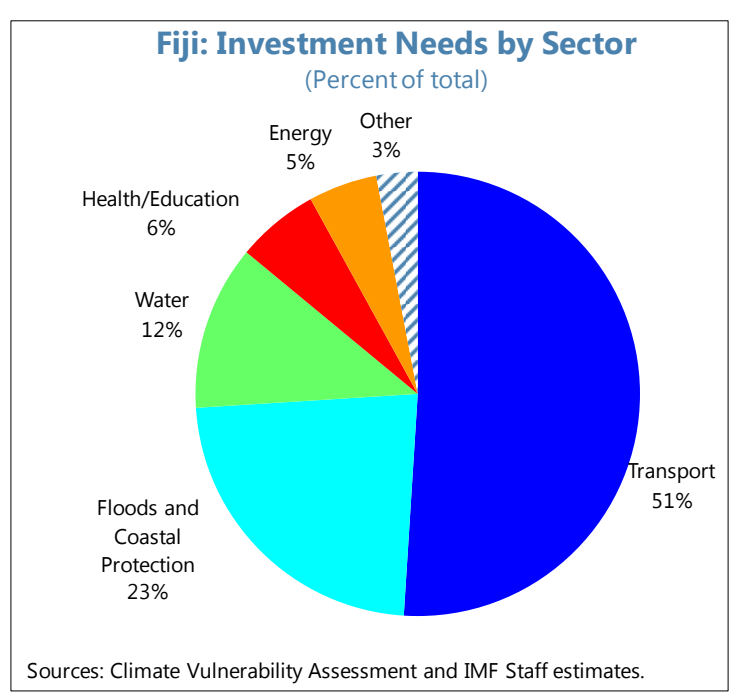

\section{Bangladesh}

6. The Bangladesh authorities are taking steps to address disaster and climate vulnerability. In 2014 the authorities introduced a Climate Fiscal Framework (CFF) to monitor public spending on climate change. The CFF is integrated in the medium-term budgetary framework and the tracking methodology is supported by the latest budget accounting classification system, developed with IMF support.

\section{In addition, the Bangladesh Planning Commission has formulated the Bangladesh Delta}

Plan 2100. Under the plan, mitigation and adaptation measures will focus on flood protection, river erosion control, river management including navigability, water supply and waste management, and flood control and drainage.

\section{Meanwhile, as of May 2018, Bangladesh has received grants from the Green Climate Fund} amounting to $\$ 85.4$ million for three climate change projects. The Bank of Bangladesh has issued Policy Guidelines of Green Banking for scheduled banks and nonbank financial institutions (NBFIs). These cover green banking policy and governance, the incorporation of environmental risk in credit risk management, and the creation of a Climate Risk Fund. Banks and NBFIs are requested to allocate ten percent of their corporate social responsibility budgets to finance economic activities in flood, cyclone, and drought-affected areas.

\section{Still, more actions are needed for sufficient financing to address natural disasters and} climate change. A clear priority for Bangladesh is to raise domestic revenue from its current low base. At less than ten percent of GDP, Bangladesh's tax revenue is insufficient to adequately invest in mitigation activities and adaptation infrastructure while concurrently addressing other SDG 2030 objectives. A carbon tax could raise significant revenues and a related priority should be to address energy subsidies. Additional longer-term investments in infrastructure are also needed with a greater fiscal buffer to cope with the immediate consequences of potential natural disasters. 


\section{Annex IV. The Structure of Cat Bonds}

\section{Cat bonds are not materially different from traditional insurance, but are structured}

differently. They can help governments transfer disaster risk to capital markets, where investors are looking to diversify their portfolio with assets that are not correlated with the stock market or the economic cycle. As an alternative to traditional insurance, cat bonds have been rarely used by sovereigns to date.

- A cat bond is a fixed income security where the coupon paid to the bondholders is enhanced by a premium commensurate to the risk from losing part or all the invested capital if a predefined natural disaster occurs. The premium paid by the sovereigns to date has averaged 1.9 times the expected loss for the investor, but this "insurance multiple" has ranged from 1.2 to 3.2 times depending on the risk metrics of the coverage.

- Under a typical catastrophe bond structure, a special purpose vehicle (SPV) is set up to intermediate the payments. The SPV issues the cat bond to investors and the SPV in turn invests the money it receives from investors in highly rated securities. The government pays the interest plus premium to the SPV, which is used - along with the interest the SPV makes from the investment in securities - to pay the coupon to the cat bond investor. The issuance, importantly, does not increase the debt stock of the sovereign since the SPV issues the debt. If a qualifying natural disaster that meets the trigger conditions occurs and payout is activated, the SPV will liquidate the investments required to make the payment to the government according to the terms of the cat bond transaction. If no trigger event occurs, then the investment is liquidated at the end of the cat bond term and the principal is repaid.

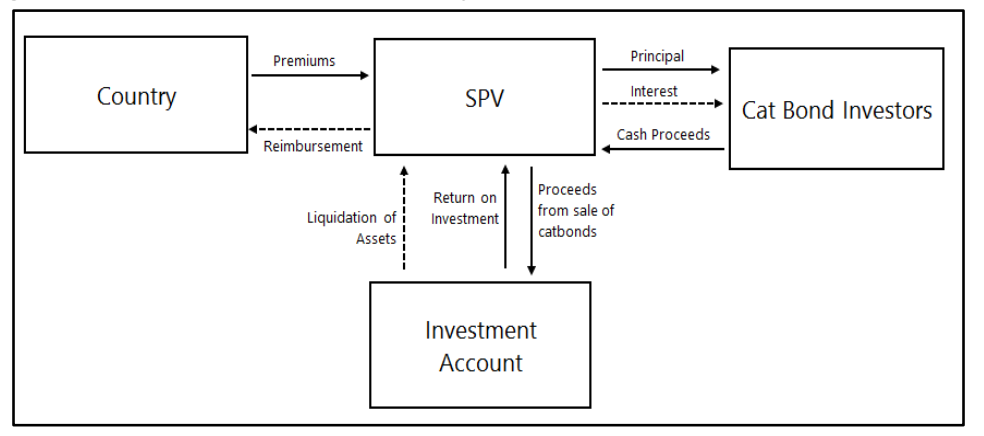

2. Key challenges to accessing cat bonds include (i) the high costs, particularly when fiscal space is constrained, (ii) the use of parametric triggers which need to be calibrated carefully to meet the country's needs, and (iii) capacity constraints in understanding the cat bonds better and communicating its limitations. These challenges are partially mitigated where the World Bank acts as an intermediary, providing cost savings for issuing countries. While only Mexico and Turkey have issued individual cat bonds so far, the Bank facilitated issuance of a first joint sovereign cat bond for members of the Pacific Alliance (Chile, Colombia, Mexico and Peru), delivering cost savings and record-low premium rates stemming from high investor demand for diversification, albeit without pooling the risks. 


\section{Annex V. Optimal Risk Transfer in Smaller vs. Larger Countries}

In choosing how much disaster risk to transfer to insurance, countries face a trade-off between the implications of this insurance for debt and for growth. The nature of this trade-off and the optimal risk transfer will vary across countries depending on size, exposure to disasters, fiscal space, and risk aversion to growth losses.

1. For all countries, the best growth-debt tradeoff is provided by packages that have the lowest insurance multiple, that is, packages cost the least relative to the expected payout (green and yellow dots on the top of the trade-off curve in chart 1). These provide the best value for money from the sovereign's perspective. In staff's analysis, packages with the lowest insurance multiples are also the ones that have the lowest deductibles, that is, where insurance starts with higher-frequency disasters.

\section{In many other respects, risk transfer decisions faced by larger (less exposed) countries are different from those of smaller and more exposed ones.}

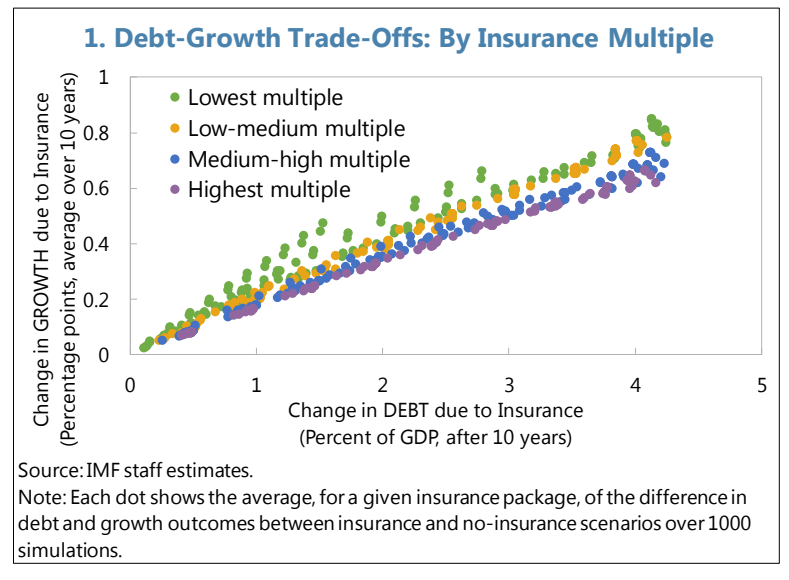

- The implications of insurance. For smaller countries, the cost of protecting growth is higher because disaster losses and therefore insurance premia are larger as a share of GDP, adding more to debt. The debt and growth implications of insurance for larger, less exposed, states are significantly smaller by comparison (chart 2).

- Different tradeoffs due to payout limits. Larger countries may face binding constraints on insurance payouts (e.g., US\$100 million in the case of CCRIF), which also limit its premium payments (creating the boomerang shape in chart 2). This de facto eliminates the tradeoffs and shifts optimal risk transfer toward

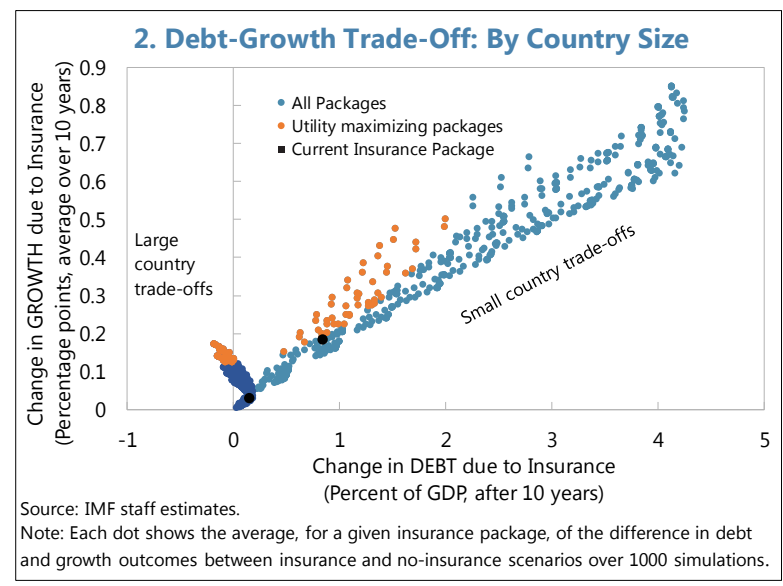
packages that provide maximum growth protection. For smaller countries, the strong trade-off between debt and growth may force a more debt-biased choice, with less expensive package that provide less growth protection.

- Smaller countries' higher risk aversion may imply a need for a growth-biased, but prohibitively costly, optimal insurance; choices improve under donor support. Smaller countries with large exposure are likely to be more risk averse to growth losses or to have stronger preferences for protecting growth rather than reducing debt. This means that they would be seeking higher 
insurance coverage with more growth protection as an optimal strategy (orange dots in chart 3), but this can carry a prohibitive cost with large debt implications. Actual small country coverage is thus often less than optimal (red dot in chart 3). A discount on the insurance premium (e.g., through donor support) would allow countries to choose more expensive packages that provide better coverage and hence growth protection (chart 4).
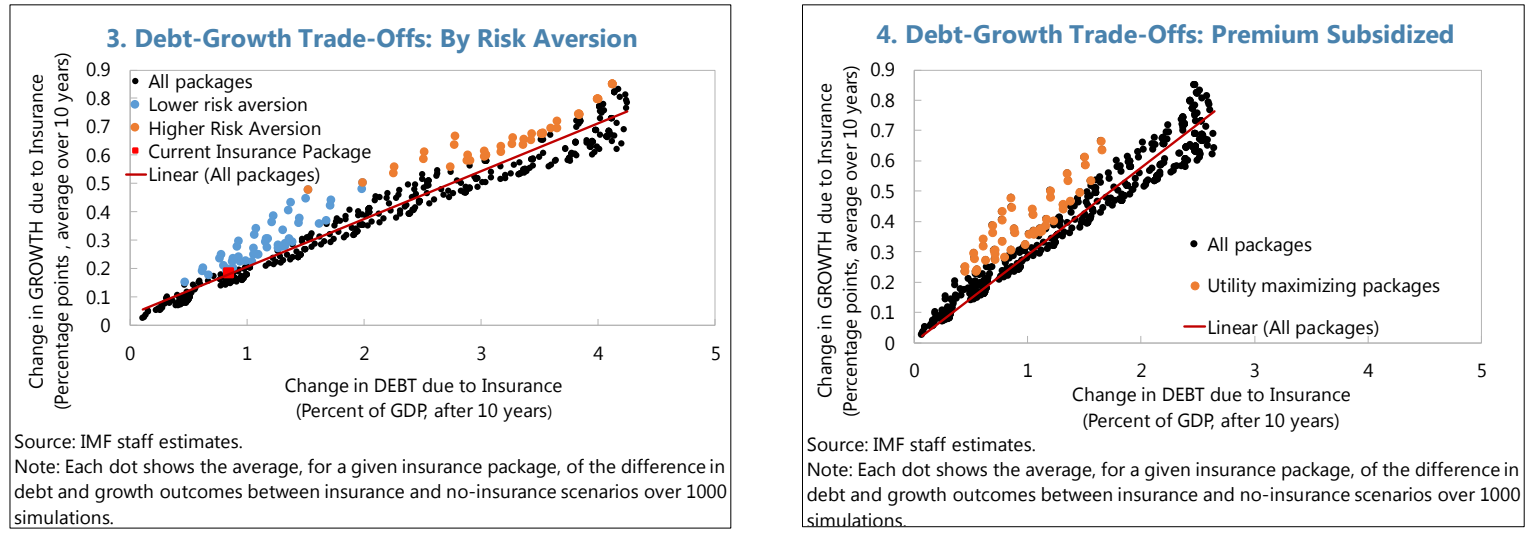

- Borrowing constraints increase insurance benefits. If borrowing capacity is limited relative to the size of the disasters, insurance is more likely to relieve the constraint on financing disaster losses, therefore providing larger growth benefits relative to countries where borrowing constraints are less binding (chart 5). ${ }^{1}$ An alternative way of interpreting this is that if countries anticipate assistance following disasters (akin to a non-binding borrowing constraint), they may opt for lower insurance coverage due to the perceived smaller benefits.

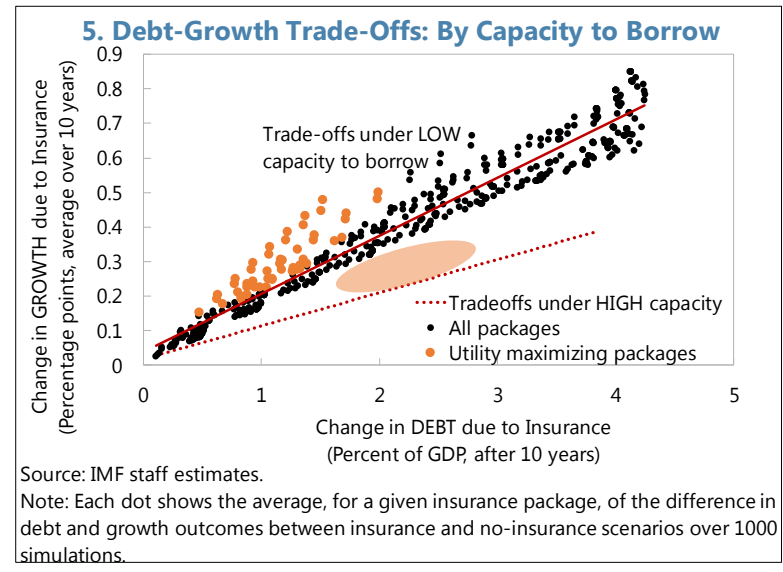

\footnotetext{
${ }^{1}$ At the same time, since larger capacity to borrow would provide an overall better protection to growth, it would also reduce the debt ratios, helping offset more the increases in debt due to insurance premia.
} 


\section{Annex VI. Investing in Pillars I and II - Illustrations for the ECCU and Pacific Islands}

\section{ECCU}

\section{Estimating the costs and benefits of resilience building and incorporating them into a} realistic medium-term macroeconomic framework is integral to building a viable Disaster

Resilience Strategy. Some of this work has been initiated in the context of staff consultations with the ECCU countries, where inadequate preparedness against natural disasters and weak fiscal performance represent two critical vulnerabilities (ECCU, 2018):

- Benefits. Based on model simulations tailored to capture key features of small states affected by natural disasters, staff estimates that scaling up resilient investment in the ECCU to 80 percent of the capital stock would increase potential output by 3-11 percent over the long-term, with a growth dividend of 0.1-0.4 percent per year during the transition to the new steady state (left hand chart). In addition, there are GDP gains of 0.7-2.7 percent of GDP a year from reduced damages and losses from natural disasters.

- Costs. The additional near-term fiscal costs of resilient investment would, however, open a transitional financing gap in the range of 0.4-1.5 percent of GDP per annum, drawing on the same model (see blue bar in right-hand chart). In addition, if countries aimed to cover 99 percent of the fiscal cost of natural disasters through self-insurance, maximum insurance coverage under the regional pool and contingent borrowing, the additional fiscal costs would range between $0.5-1.8$ percent of GDP in the ECCU but would gradually decline as resilience is built (orange bar in right-hand chart).
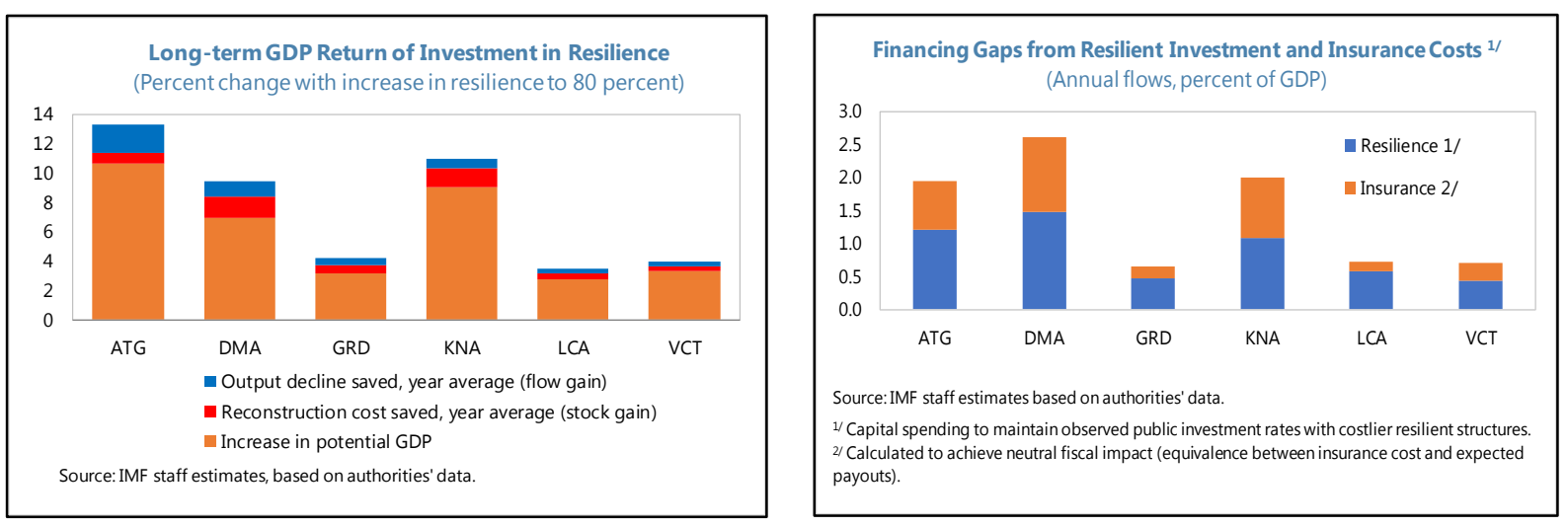
2. However, the transition from standard to resilient capital has upfront fiscal costs, with returns materializing only later. Without fiscal consolidation and in the absence of concessional financing, public debt would exceed the regional debt target of 60 percent of GDP by 2030 by 4-20 ppts of GDP owing to the higher cost of resilient capital (only about half of the public capital stock would be resilient by 2030 at the current investment rates).

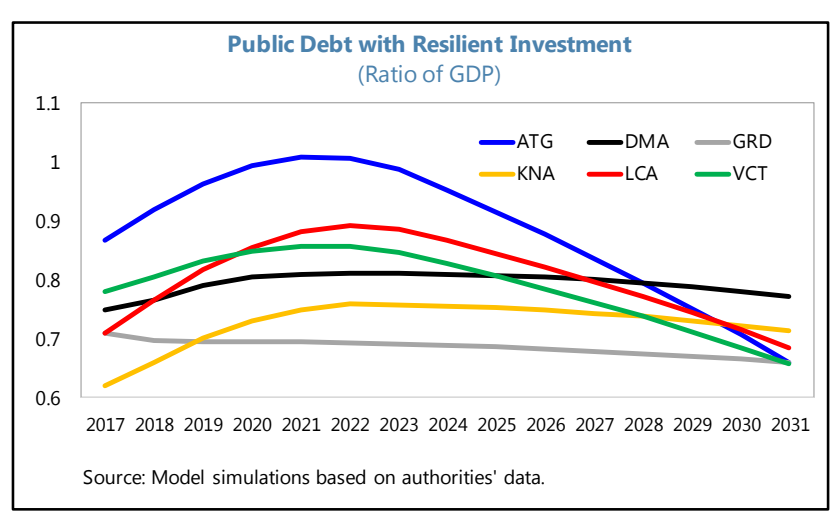

\section{The Pacific Islands}

3. Staff studies focused on Solomon Islands and Vanuatu, extending the Debt Investment Growth framework to allow government investment in both standard and climate-resilient infrastructure (Marto, Papageorgiou, and Klyuev, 2017). Model simulations considered the islands' vulnerabilities to natural disasters, low public investment efficiency, and limited access to financing. Staff found that although conventional infrastructure has a more favorable effect on growth and private investment in the short term, climate-resilient infrastructure is more likely to be associated with lower public debt and higher growth in the long term, despite its higher cost. Supportive reforms, including strengthening public investment management, are essential to boost the gains from resilient investments and should be pursued without delay given that they require time to bear fruit. Tapping external concessional financing from development partners would be optimal since domestic borrowing can crowd out the private sector.

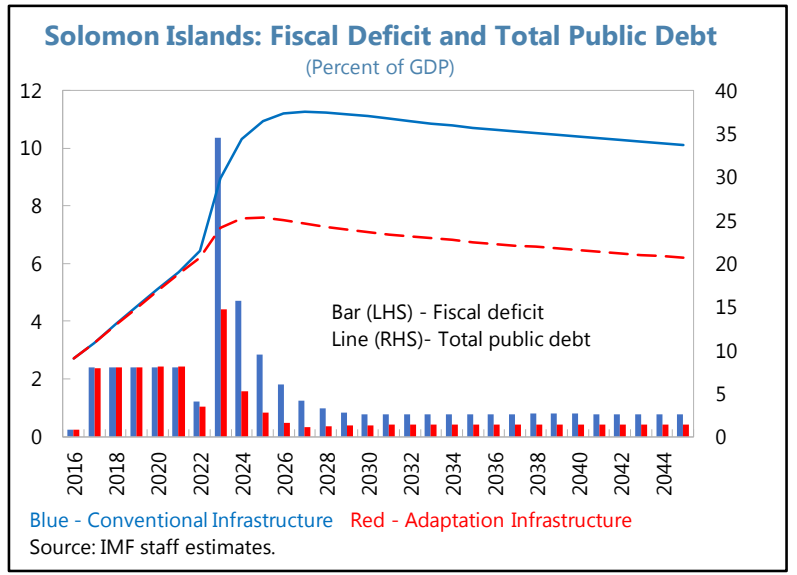

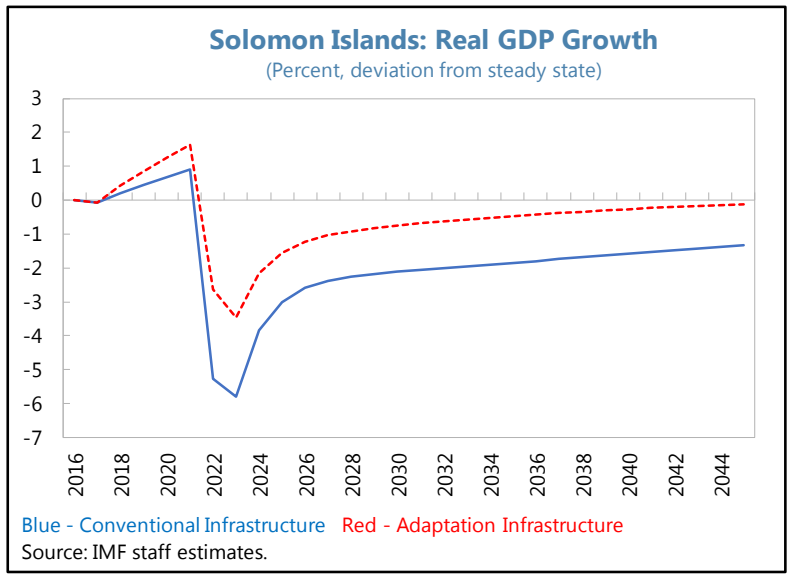




\section{Annex VII. Advanced and Emerging Asia Pacific Region: Examples of Disaster Resilience Building}

Lessons from other advanced and emerging markets emphasize: 1) the need for a cross-cutting approach to disaster resilience to make it central in development planning and the budgetary process, with clear planning at ministry, provincial and local government level; 2) taking into account the maintenance needs and periodic upgrading of infrastructure; 3) consider innovative financing such as catastrophe insurance and reinsurance; and 4) improve education in disaster preparedness and focus financial inclusion efforts on individuals with limited insurance and basic financial products.

1. Japan. A long history with natural disasters has led to policies aimed at building resilience in water resources management, management of droughts and floods, earthquake and fire damage control and mitigation, and public awareness for disaster prevention. The recent bill on climate change adaptation aims to accelerate prevention and mitigation measures. Under the new act, Ministry of the Environment undertakes climate change impact assessments every five years, and the National Adaptation Plan is revised accordingly. Municipalities formulate their own Local Climate Change Adaptation Plans and are supported by the National Institute for Environmental Studies (NIES) which provides a hub of scientific information, technical support and advice to promote local adaptation, including through the Climate Change Adaptation Information Platform (A-PLAT). Examples of strengthening structural resilience include:

- Earthquake/Fire: The Tokyo Metropolitan Government has designated key disaster prevention areas as fireproof districts. The city also makes effective use of a Fireproof Promotion Program and has improved the subsidy system to make buildings fireproof and encourage joint civic/business reconstruction of old buildings.

- Flooding: physical resilience to flooding has been improved through a network of subterranean cisterns, tunnels and engines to protect the Tokyo metropolitan area from extreme flooding. Built at a cost of US $\$ 2$ billion in 2006, the Metropolitan Area Outer Underground Discharge Channel pulls in water from swollen rivers and pumps it out toward the ocean.

2. Financial resilience: Fiscal spending on aged and vulnerable infrastructure is a regular part of annual and supplementary budgets. Japan's institutionalized and government-funded program of "National Resilience" (kokudo kyoujinka) is in some ways more advanced than initiatives in North America, the European Union and elsewhere. Japan's resilience program, including both public and private sector spending, totaled over JP $¥ 24$ trillion (US $\$ 210$ billion) in 2013 and is projected to grow dramatically by 2020. Moreover, Japan's disaster resilience centers on renewable energy, storage and efficiency, and has become a core element of Abenomics.

3. New Zealand. Damage from natural disasters including earthquakes, tsunamis, landslips, volcanic eruptions, storms and geothermal activity is addressed by the Natural Disaster Fund, managed by a state-owned enterprise, the Earthquake Commission (EQC), with additional funding guarantees from the government. The EQC also conducts research and education in natural disaster 
preparedness. Immediate response to disasters falls under the Ministry of Civil Defence and Emergency Management, with a formal strategy in place, that will be reviewed and renewed in 2019. In the event of a natural disaster, the EQC insures for land damage, and up to a cap of NZ $\$ 100,000$ on residential damage and NZ $\$ 20,000$ on contents. 2019 will probably see the cap amended to NZ\$150,000, with contents coverage removed - the first amendment of the cap since its definition in 1993. The remainder is covered by private insurance and is a precondition for the provision of EQC insurance. After major events, the government provides immediate emergency aid, and then the EQC's Natural Disaster Fund pays out insurance claims in tandem with private insurers. The Natural Disaster Fund is funded by insurance premia, but it was exhausted by the Canterbury and Kaikoura earthquake claims, leading to extra funding from the government in the near term, as guaranteed by law. Expected EQC revenues from insurance levies and liabilities from current and expected claims are tracked as part of the government's budget, and there are comprehensive reporting requirements from the EQC.

4. Philippines. The Disaster Risk Reduction and Management Act of 2010 marked a shift of policy focus from disaster response to risk reduction and preparedness. A key reform was the integration of disaster risk reduction as a cross-cutting policy priority in development planning and budgeting. In 2015, the Department of Budget and Management developed a Climate Change Expenditure Tagging system that identifies government agencies' climate change-related expenditures. The budget allocated to this category has been rapidly rising, including through the National Disaster Reduction and Management Fund focused on climate-related infrastructure investment.

5. Financial resilience. The Philippine government has strengthened financial resilience through innovative approaches. The government's Disaster Reduction Financing and Insurance Strategy combines a variety of risk financing instruments to protect against events of different frequency and severity. A recent initiative is the introduction of a catastrophe insurance program (US $\$ 206$ million) to protect government assets. Under the program, a government-owned insurance agency would provide protection against catastrophe risks to the national government and participating local governments. Subsequently, the risks would be passed on to a group of private international reinsurance companies through a competitive bidding process with the World Bank acting as an intermediary. This program complements the government's existing natural disaster-related reserves and contingency credit lines, as well as the central bank's financial inclusion initiative targeted for people with limited access to insurance and other basic financial products.

6. Indonesia. The 2007 law on disaster management established the legal basis for organizing disaster management in Indonesia, including prevention, mitigation, emergency response, rehabilitation and reconstruction. The government established the National Disaster Management Agency (BNPB) in 2008, supported at the regional level by the Provincial Agency for Disaster Management (BPBD) and districts/cities agencies. The 2015-2019 National Medium-Term Development Plan (RPJMN) aims to reduce risk, increase the resilience of national and local governments, and support communities facing disasters. The BNPB Strategic Plan is aligned with both the medium and long-term development plans. Support for disaster risk management has 
grown, with BNPB's budget allocation for disaster management increasing 500 percent from 2010 to 2014. However, at the provincial and lower levels agencies, personnel, equipment, and budget are still limited. The government spends US $\$ 300$ to US $\$ 500$ million annually on post-disaster reconstruction. Costs during major disaster years reach 0.3 percent of national GDP and as high as 45 percent of GDP at the provincial level. 